\title{
Transcriptomic and proteomic analysis of a compatible tomato-aphid interaction reveals a predominant salicylic acid-dependent plant response
}

\author{
Valentina Coppola', Mariangela Coppola', Mariapina Rocco², Maria Cristina Digilio', Chiara D’Ambrosio³, \\ Giovanni Renzone ${ }^{3}$, Rosanna Martinelli ${ }^{4}$, Andrea Scaloni ${ }^{3}$, Francesco Pennacchio ${ }^{1}$, Rosa Rao ${ }^{1 *}$ \\ and Giandomenico Corrado ${ }^{1}$
}

\begin{abstract}
Background: Aphids are among the most destructive pests in temperate climates, causing significant damage on several crops including tomato. We carried out a transcriptomic and proteomic study to get insights into the molecular mechanisms and dynamics of the tomato response to the Macrosyphum euphorbiae aphid.

Results: The time course analysis of aphid infestation indicated a complex, dynamic pattern of gene expression. Several biological functions were affected and genes related to the stress and defence response were the most represented. The Gene Ontology categories of the differentially expressed genes (899) and identified proteins (57) indicated that the tomato response is characterized by an increased oxidative stress accompanied by the production of proteins involved in the detoxification of oxygen radicals. Aphids elicit a defense reaction based on the cross-communication of different hormone-related signaling pathways such as those related to the salicylic acid (SA), jasmonic acid (JA), ethylene and brassinosteroids. Among them, the SA-signaling pathway and stress-responsive SA-dependent genes play a dominant role. Furthermore, tomato response is characterized by a reduced accumulation of photosynthetic proteins and a modification of the expression of various cell wall related genes.

Conclusions: Our work allowed a more comprehensive understanding of the signaling events and the defense dynamics of the tomato response to aphids in a compatible interaction and, based on experimental data, a model of the tomato-aphid molecular interaction was proposed. Considering the rapid advancement of tomato genomics, this information will be important for the development of new protection strategies.
\end{abstract}

Keywords: Solanum lycopersicum, Macrosiphum euphorbiae, Plant-insect interactions, Defense, Salicylic acid, Jasmonic acid

\section{Background}

The investigation of plant defense mechanism offers interesting information about genes suitable to control agricultural pests [1]. Studies on crop plants, for which an increasing number of genomic sequencing projects have been completed, are essential to translate the knowledge gained on model species into indications

\footnotetext{
*Correspondence: rao@unina.it

'Dipartimento di Agraria, Università degli Studi di Napoli Federico II, 80055 Portici, NA, Italy

Full list of author information is available at the end of the article
}

useful to select superior genotypes and to develop more efficient control strategies.

Aphids (Hemiptera: Aphididae) are the largest group of phloem-feeders and among the most destructive insect pests of cultivated plants in temperate regions [2]. These insects have a unique feeding strategy and impose a distinctive stress on plants, being able to directly and indirectly damage crops by removing photoassimilates and introducing viruses. Most aphids feed on contents of vascular tissues by inserting piercing mouthparts (i.e. the stylet) hence, causing a limited mechanical damage.

\section{Biomed Central}


However, aphids have the ability to manipulate host plant physiology and to introduce effectors that alter defense signaling [3,4]. Differently from caterpillars, aphids establish a prolonged interaction with the attacked plant tissue. Currently, little is known on how aphids can feed for an extended period of time from a single sieve element, despite the ability of plants to quickly repair damaged tissues. For all these reasons, it is widely accepted that plant response to phloem-feeding aphids is distinct from that to chewing insects, which crush leaf tissue, and to thrips and spider mites, which ingest the content of individual cells $[5,6]$.

The signs and symptoms of aphid attack can be diverse, and vary according to the plant species (and the tissue attacked), to the aphid species and biotype, and their combination [6]. Therefore, it is likely that host molecular response is specific for a certain plant-aphid interaction. Plant-aphid interaction has been studied mainly at the transcriptional level, while proteomic data are only available for wheat attacked by cereal aphids [7]. Overall, it is believed that aphids trigger in plants responses that overlap with those related to wounding and fungal pathogens [8-10]. Transcriptional profiling pointed out variations related to Reactive Oxygen Species (ROS) generation or scavenging, primary metabolism, cell wall fortification and synthesis of secondary metabolites [10-15]. In different interactions it has been observed that plants activate the jasmonic acid (JA)- and/or salicilic acid (SA)-dependent pathways, which should regulate aphid defense genes through their antagonistic or synergistic cross-communication. For instance, the expression of SA-responsive genes increases substantially following the attack of Myzus persicae on aphid-susceptible Arabidopsis and celery, and of Schizaphis graminum on aphid-susceptible sorghum, while changes in JAdependent mRNA levels were more limited [9-12]. Moreover, the induction of the SA-pathway in aphidresistant wheat challenged by Diuraphis noxia also supports a predominant role of this molecule in the resistance mechanism [16]. However, gene expression profiling indicated that both SA- and JA-responsive genes were substantially induced in Arabidopsis by Brevicorynae brassicae or $M$. persicae attack $[17,18]$. These apparent discrepancies may be partly explained considering that in a compatible interaction, phloemfeeders may antagonize the innate plant wound responses to make the plant a more suitable host [5]. Currently, the effect of SA induction on aphid performance in compatible interactions, as well as its antagonism with the JA pathway, have not been fully elucidated (reviewed in [1]).

Towards this aim, we studied at the transcriptional and proteomic level the defense response of tomato plants (Solanum lycopersicum) against the potato aphid
(Macrosiphum euphorbiae), a polyphagous pest of remarkable economic importance [19]. In tomato, symptoms include mild leaf curling, chlorosis and necrosis, resulting in defoliation and significant yield loss when pest population density is high [19]. In the present work, a timecourse transcriptomic analysis based on microarrays was carried out to investigate tomato responses during a compatible interaction. In addition, to achieve a more detailed understanding of the tomato response, we performed a proteomic analysis by 2-D electrophoresis combined with MS technology. Our work provided the first combined analysis of the tomato-aphids molecular interaction.

\section{Results}

Expression profiling of tomato genes responsive to $M$. euphorbiae feeding

To profile the variation in gene expression in tomato following the establishment of a compatible interaction with the $M$. euphorbiae, we analysed plants 24,48 and 96 hours after infestation. In our data analysis, three filtering criteria were used to identify differentially expressed genes: a two-fold change in transcript levels between unifested and infested plants, a $p<0.05$ and a significant match between the oligonucleotide probe and a tomato gene. Taking into account the three time points, 999 annotated probes were significantly differentially expressed (Table 1). All differentially expressed probes were grouped according to the similarity of their expression profiles at the three data-points by cluster analysis. The dendrogram indicated that, as expected, the three biological replicates for each time point assort together, showing a good congruence (Figure 1). Moreover, the heat-map illustrates a weak linkage among the three conditions, with the most intense transcriptional response at $48 \mathrm{~h}$. Cluster analysis identified groups of similarly behaving transcripts that have different expression trends, highlighting a relevant dynamism of gene expression in tomato. The recent release of the tomato genome sequence allowed us to map the microarray probes on the genome sequence, thus providing the opportunity of a more accurate functional annotation of the array. A similarity analysis, performed against SGN Tomato Unigene database for the differentially expressed 999 probes, identified 819 genes. Specifically, the data indicated that at $24 \mathrm{~h}$ after infestation, 148

Table 1 Tomato probes (999) differentially expressed in response to $M$. euphorbiae feeding at each sampling time

\begin{tabular}{cccc}
\hline Time (hpi)* & \multicolumn{3}{c}{ Number of probes } \\
\cline { 2 - 4 } & Up-regulated & Down-regulated & Total \\
\hline 24 & 87 & 95 & 182 \\
48 & 391 & 377 & 768 \\
96 & 23 & 26 & 49 \\
\hline
\end{tabular}

* hpi: hours post infestation. 


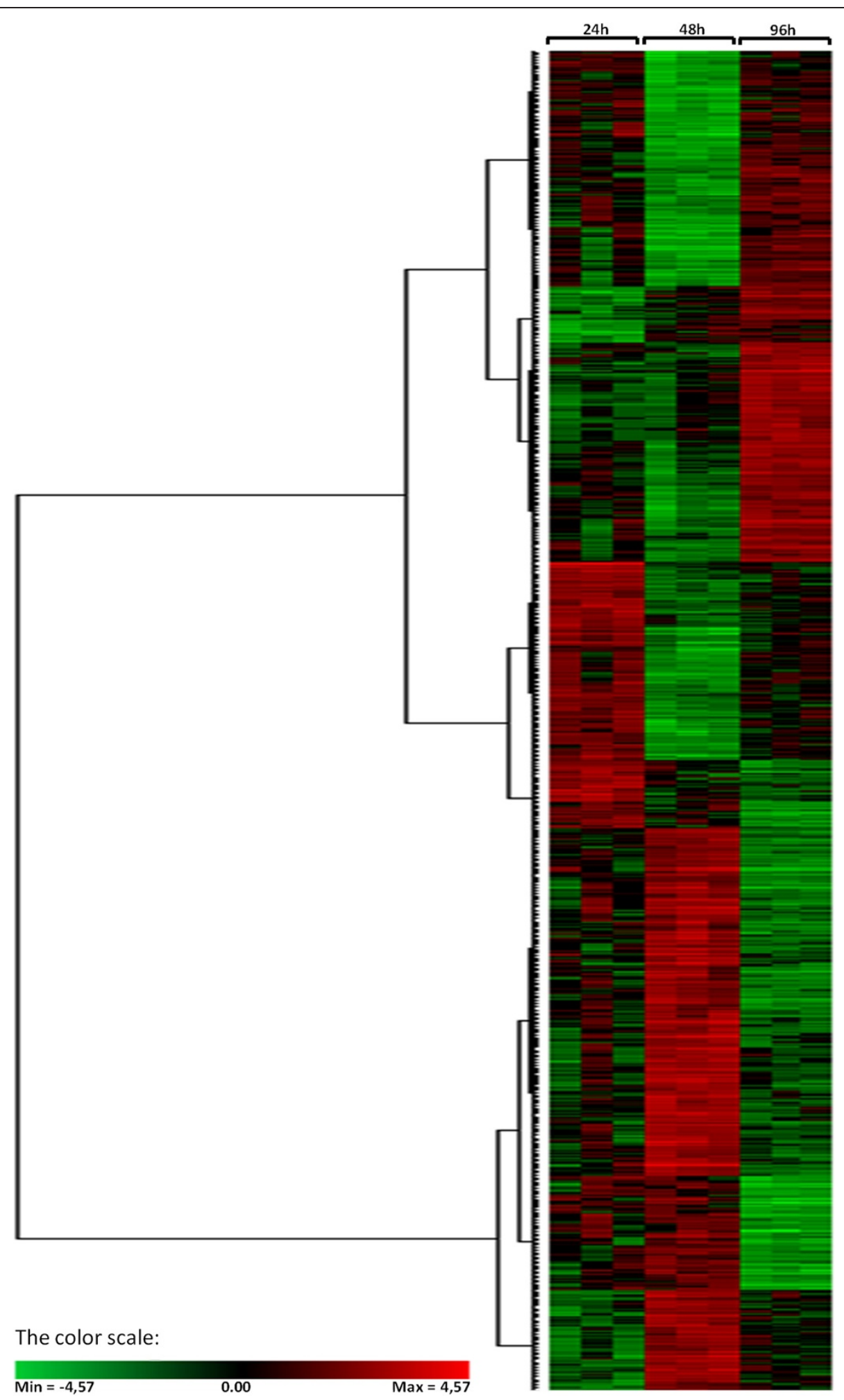

Figure 1 Hierarchical cluster of all differentially expressed probes. Distances were calculated using the Pearson similarity and agglomeration was performed according to the Ward's minimum variance algorithm. The heat-map diagram shows the relative expression level at the three time points (24, 48 and 96 hours post infection). Gradation from red to green represents strong up-regulation to strong down-regulation on a log scale. In each time point, each colored column represents a single biological replicate. 
genes (72 up and 76 down) were significantly affected by aphid infestation. The number of responsive genes at $48 \mathrm{~h}$ was 637 (320 genes up and 317 down), while at 96 h, 34 genes (17 up and 17 down) were differential expressed. The complete list of differentially expressed genes, including their expression levels in all three time points, is accessible as supplementary material (Additional file 1: Table S2, S3, S4). The Venn diagram (Figure 2) shows the intersections between the differentially expressed genes at the three time points. For all combinations, the overlap was limited, and only three genes were significantly affected throughout the whole time course (Table 2), indicating that the induction of most response genes is transient [20]. It is therefore noteworthy that two genes encode transcription factors belonging to the WRKY family, important regulators of SA-dependent defense responses. Specifically, the WRKY6 gene codes for a protein that in Arabidopsis thaliana has the highest similarity to the AtWRKY70 (identity: 41\%; similarity: 58\%; e-value: 1e36), considered its orthologue [21]. This is strengthened by the presence in the WRKY6 promoter region of the core binding consensus sequence for the AtMYB44, which was recently described as a transcriptional activator in Arabidopsis [22]. The tomato WRKY46 protein is most similar to AtWRKY40 (identity: 43\%; similarity: 54\%; evalue: 2e-54). The AtWRKY40 gene is associated with pathogen response and it was also induced by the aphid $B$. brassicae [14]. The third gene codes for a GDSL esterase/ lipase. GDSL-lipase belongs to a subfamily of lipolytic enzymes which appear to be primarily involved in the regulation of plant development and morphogenesis [23]. Some GDSL-lipase genes have been involved in plant defense because of their induction by SA and pathogens [24-26].

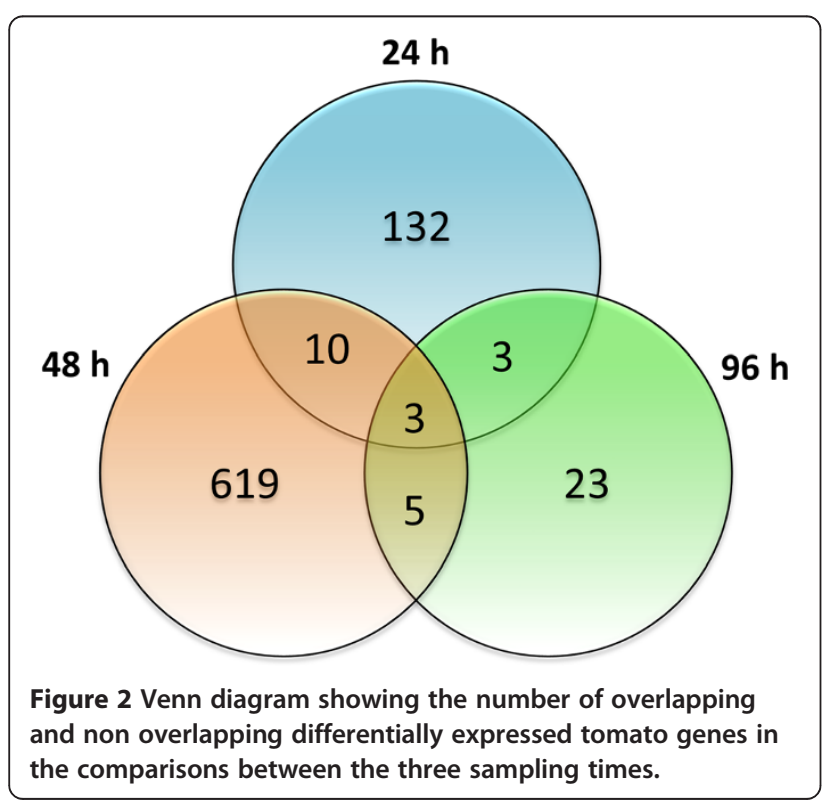

Table 2 Shared genes differentially expressed in response to $M$. euphorbiae feeding at the three sampling times

\begin{tabular}{|c|c|c|c|c|c|}
\hline \multicolumn{3}{|c|}{ Fold change } & \multirow[t]{2}{*}{ SGN Unigene } & \multirow[t]{2}{*}{ Description } & \multirow{2}{*}{$\begin{array}{c}\mathrm{GO} \\
\text { annotation* }\end{array}$} \\
\hline $24 \mathrm{~h}$ & $48 \mathrm{~h}$ & $\overline{96 h}$ & & & \\
\hline \multirow[t]{2}{*}{3.5} & \multirow[t]{2}{*}{8.5} & \multirow[t]{2}{*}{3.6} & \multirow[t]{2}{*}{ Solyc09g015770.2.1 } & \multirow{2}{*}{$\begin{array}{c}\text { WRKY } \\
\text { transcription } \\
\text { factor } 6\end{array}$} & $\begin{array}{l}\text { P: regulation of } \\
\text { transcription; }\end{array}$ \\
\hline & & & & & $\begin{array}{l}\text { F: transcription } \\
\text { factor activity; } \\
\text { C: transcription } \\
\text { factor complex }\end{array}$ \\
\hline \multirow[t]{2}{*}{10.7} & \multirow[t]{2}{*}{124.6} & \multirow[t]{2}{*}{31.7} & \multirow[t]{2}{*}{ Solyc08g067340.2.1 } & \multirow{2}{*}{$\begin{array}{c}\text { WRKY } \\
\text { transcription } \\
\text { factor } 46\end{array}$} & $\begin{array}{l}\text { P: regulation of } \\
\text { transcription; }\end{array}$ \\
\hline & & & & & $\begin{array}{l}\text { F: transcription } \\
\text { factor activity; } \\
\text { C: transcription } \\
\text { factor complex }\end{array}$ \\
\hline \multirow[t]{3}{*}{3.13} & \multirow[t]{3}{*}{-2.49} & \multirow[t]{3}{*}{2.22} & \multirow[t]{3}{*}{ Solyc11g006250.1.1 } & \multirow[t]{3}{*}{$\begin{array}{l}\text { GDSL } \\
\text { esterase/ } \\
\text { lipase }\end{array}$} & $\begin{array}{l}\text { P: lipid } \\
\text { metabolic } \\
\text { process; }\end{array}$ \\
\hline & & & & & $\begin{array}{l}\text { F: hydrolase } \\
\text { activity; }\end{array}$ \\
\hline & & & & & $\begin{array}{l}\text { C: cytoplasmic } \\
\text { membrane- } \\
\text { bounded } \\
\text { vesicle }\end{array}$ \\
\hline
\end{tabular}

* The GO term associations for the gene product were retrieved and selected from the best blast matches at the AmiGO website (http://amigo. geneontology.org). P: biological process; F: molecular function; C: cellular component.

\section{Dynamics of the tomato response to aphids}

To underline the biological objective to which the differentially expressed genes contribute, we used the Blast2GO tool to provide Gene Ontology (GO) terms association. The differentially expressed genes were distributed in eleven categories, namely "cell maintenance", "transcription", "cell wall modification", "stress and defense response", "signal transduction", "photosynthesis", "primary metabolism", "secondary metabolism", "protein metabolism", "transport" and "unknown function".

The investigation of the tomato transcriptome following aphid attack highlighted the activation of a wide and complex response, as the transcriptional reconfiguration involved a broad range of biological processes in a different way. Since the absolute number of differentially expressed genes was different at the three time-points, Figure 3 shows the changes of $M$. euphorbiae-induced responses as percentage. Overall, the most relevant differences were in the category "stress and defense response", followed by "primary metabolism" and "transcription". The "signal transduction" and "protein metabolism" processes peaked at $48 \mathrm{~h}$. A maximum variation of up-regulated genes at $96 \mathrm{~h}$ was found for "primary metabolism", "transport" and "stress defense and response". For the biological process "transport" the proportion of down-regulated genes increased in time, but considerably increased at $96 \mathrm{~h}$ for "stress defense and response". This biological process 
A stress and defence response signal trasduction

transcription

wall modification

photosynthesis

primary metabolism

protein metabolism

secondary metabolism

cell maintenance

transport

unknown

B

stress and defence response signal trasduction

transcription

wall modification

photosynthesis

primary metabolism

protein metabolism

secondary metabolism

cell maintenance

transport

unknown

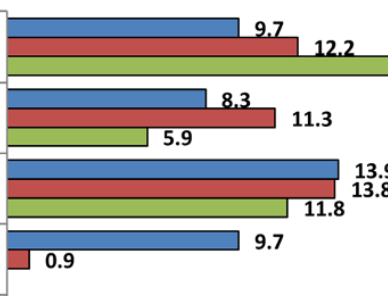

8.3

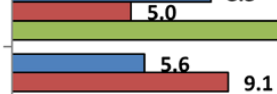

9.1
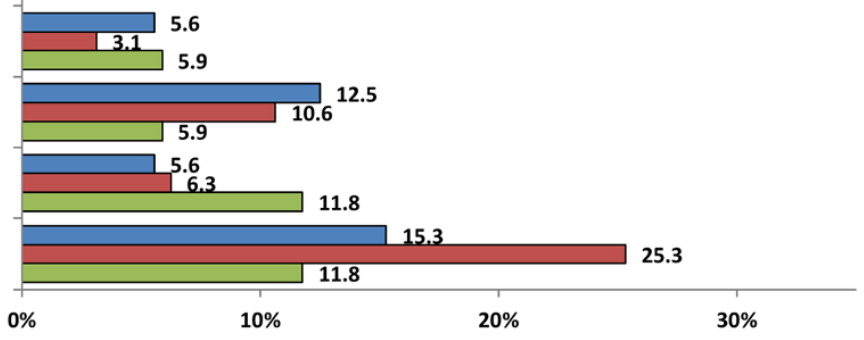

Down-regulated

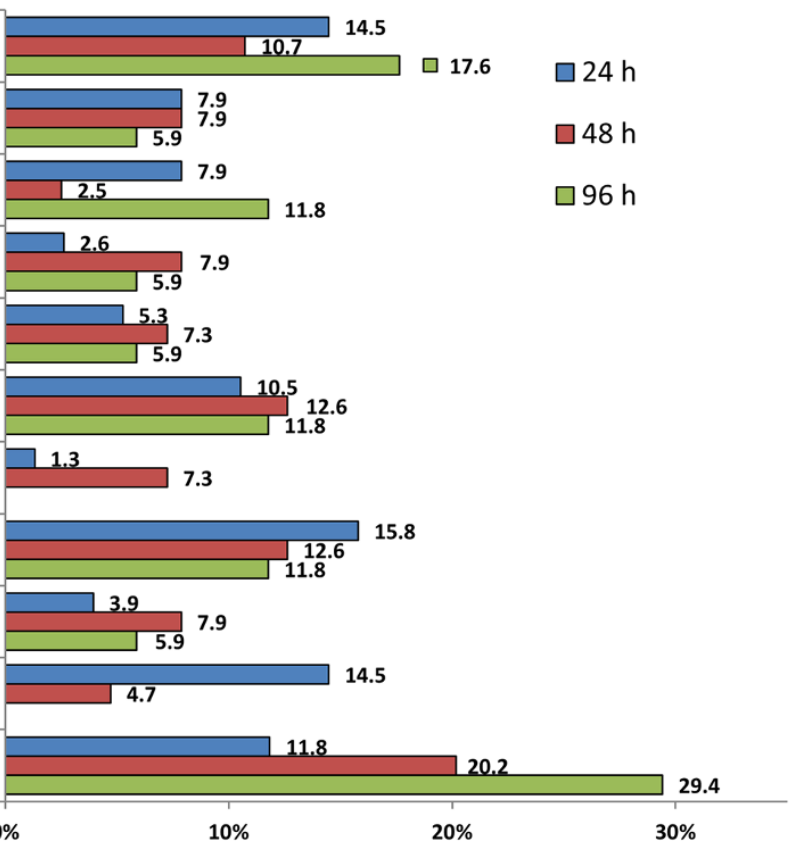

Figure 3 Functional overview of the differentially expressed genes. Functional analysis of the up-regulated (A) and down-regulated (B) tomato genes following M. euphorbiae attack at the three harvest times. Differentially expressed genes were assigned to categories according to GO biological process terms. The X-axis indicates the percentage of the Unigenes in each category out of the total number of differentially-expressed genes for each harvest time.

showed the maximum variation of up and down regulated genes at $96 \mathrm{~h}$. With the progress of aphid infestation, the rate of up regulated genes involved in "photosynthesis", "cell maintenance" and "cell wall modification" gradually decreased in time. For these processes the percentage of downregulated genes peaked at $48 \mathrm{~h}$.

The classification of differentially expressed genes according to GO molecular function terms, indicated that "hydrolase activity" was the most frequent in the first 
(24 h) and last time (96 h) of infestation (Figure 4). Interestingly, "calcium ion binding", "kinase activity" and "receptor activity" were the molecular functions present only at $24 \mathrm{~h}$ and $48 \mathrm{~h}$, implying that the differentially expressed genes of these categories relate with the perception of aphid feeding and the mounting of a defense response. The molecular function "antioxidant activity" was activated only at $48 \mathrm{~h}$.

Overall, both the number of genes and the categories of the differentially expressed genes indicated that transcriptional re-programming is a key process of a tomato defense towards M. euphorbiae. The Gene Ontology analysis of the response dynamics showed an active, and for some processes coordinated, alteration of several biological functions. Aphid infestation mainly affects genes involved in stress response and progressively inhibits the expression of genes involved in photosynthesis and cell maintenance. However, in absolute terms the composite tomato response to aphids relies largely on genes that do not code for products directly involved in insect resistance.

\section{Tomato transcriptional response to aphids}

The aphid response genes were grouped according to their functions. For sake of simplicity, genes that participate in more than one biological processes are presented only once considering their prevalent role.

\section{Stress and defense response}

This functional category comprised genes related to defense against abiotic or biotic stress, including those involved in the response to oxidative stress. Throughout the three time points, a total of 97 genes were differentially expressed (Additional file 1: Table S2, S3, S4), making this category the most represented biological process. Among the overexpressed genes, fourteen were associated to oxidative stress, including, for instance, a gene coding for Respiratory Burst Oxidase-Like Protein (RBOHD). The majority of those genes (9) encode enzymes linked to the oxidative burst, such as four peroxidases, three glutathione S-transferases and two glutare doxins. Peroxidases code for ROS-detoxifying enzymes but they are also involved in oxidative signal transduction, regulating the redox and $\mathrm{Ca}^{2+}$ homeostasis as well as the expression of defense genes [27]. Similarly, glutaredoxins are also involved in the SA signaling pathway [28], through the reduction of the cytosolic form of NPR1 to its monomeric form [29]. Furthermore, as the ROS damage could be enhanced through the accumulation of other toxic compounds (e.g. reactive aldehydes), we observed at the same time point the induction of genes such as Aldehyde dehydrogenase 1 and Aldo/keto reductase. These play a central role in the detoxification mechanism of toxic aldehydes [30,31], which arise from the breakdown of membrane's lipids due to ROS.
Genes affected by aphid infestation were also related to the SA- (23 genes) and the JA- (8 genes) dependent pathways. Among the genes associated with the SA, there were chitinases, Pathogenesis Related (PR) proteins, and Nimin2c. The latter showed a transient boost, with the highest level of expression at $48 \mathrm{~h}$ (39,45 signal log ratio) and a reduced expression at $96 \mathrm{~h}$ of infestation $(7,52)$. Nimin genes belong to small families linked to the SAR response, essentially through the interaction with NPR1 [32,33]. In tobacco, NIMIN2 gene expression is elevated prior to the induction of the PR-1a gene, through transient PR-1 repression before SAR has fully developed [33]. While the majority of SA-related genes were over-expressed, the effect of aphid feeding on the JA-related genes was more complex. Four JA-dependent late genes (e.g.: Polyphenol oxidase (PPO), Threonine deaminase, Type I serine protease inhibitor, Serine carboxypeptidase 1) were downregulated at $48 \mathrm{~h}$. Conversely, genes coding for other antinutritive proteins such as protease inhibitors were induced at $24 \mathrm{~h}$ and 48 h. Specifically, genes encoding the Kunitz trypsin inhibitor and the Wound-induced proteinase inhibitor 2 were upregulated at $24 \mathrm{~h}$, while the induction of Proteinase inhibitor I transcripts was observed $48 \mathrm{~h}$ post-infestation, along with an Arginase and Leucin aminopep tidase. Finally, nineteen different genes typically linked to abiotic stress response showed differential expression at the three time points and included thirteen genes encoding heat shock and DNAJ chaperone proteins. These proteins play key roles in buffering physiological and developmental variations by acting at multiple levels to maintain homeostasis and or protein stability during stress [34].

The gene expression analysis indicated that the transcriptional response to the accumulation and subsequent detoxification of ROS is taking place mainly at $48 \mathrm{~h}$ following infestation. Furthermore, aphid attack activates responses most similar to salicylate-mediated gene induction, although the expression of some jasmonate-related genes is also increased.

\section{Signaling related genes}

The signaling response in plants requires a variety of messengers and thus, seventy-six genes related to signal transduction were differentially expressed in infested tomato. These included among others, the LRR receptorlike serine/threonine-protein kinase, Serine/threonineprotein kinase receptor, S-locus receptor kinase and TIR-NBS-LRR resistance protein (Additional file 1: Table S2, S3, S4). In the first and second time point, 27 genes coding for kinase receptors were affected, whereas the induction of members of this class of genes was not observed at $96 \mathrm{~h}$. This is consistent with a process of aphid recognition and response that takes place during the first phases of the attack. Among these putative cell surface 


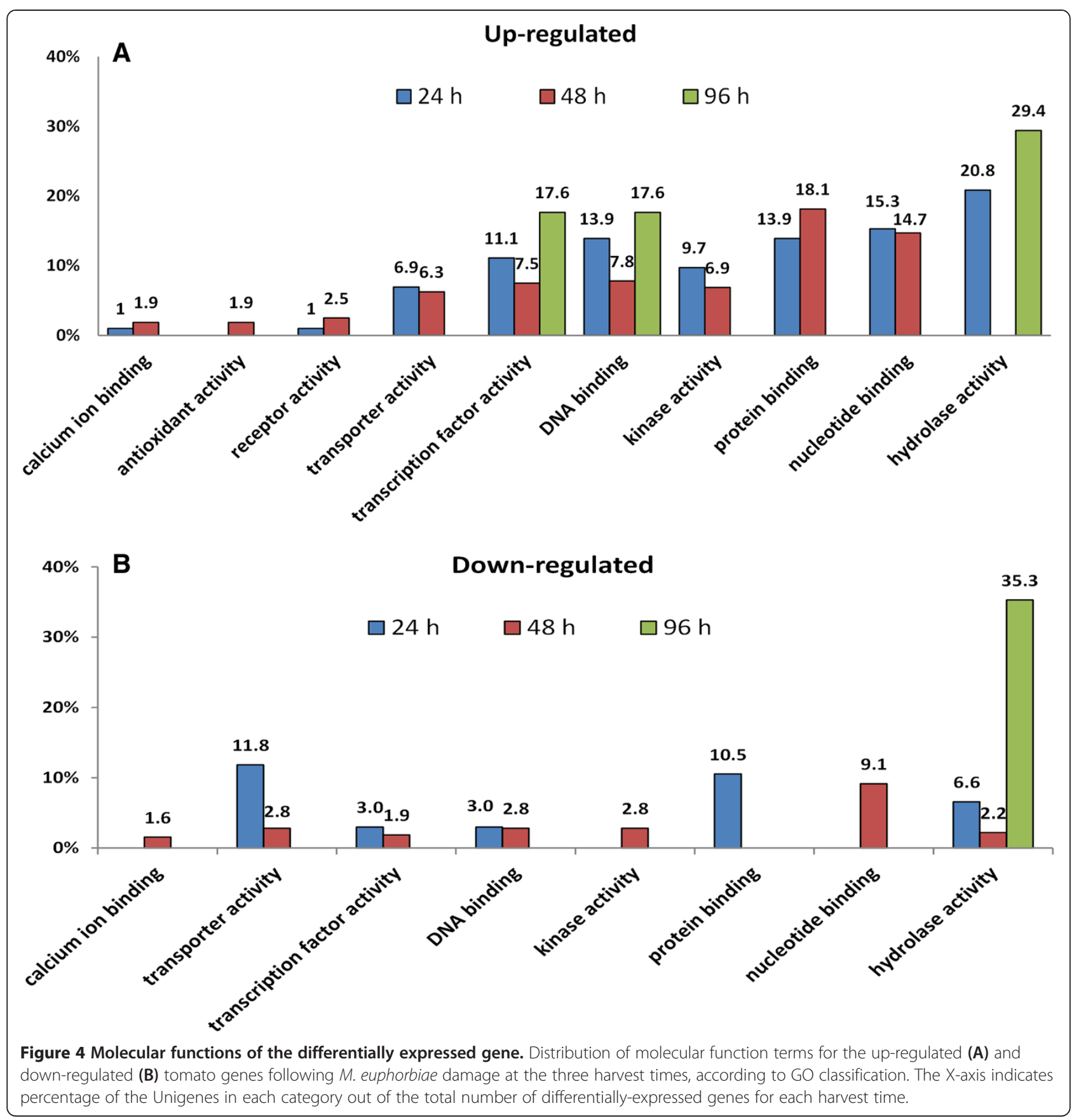

receptors, a serine-threonine protein and a lectin were the most expressed at $24 \mathrm{~h}$ and $48 \mathrm{~h}$, respectively. Moreover, twelve genes associated with signaling transduction of plant hormones (i.e.: Et, JA, ABA, brassinosteroids and auxins) were differentially expressed at $48 \mathrm{~h}$. The intracellular concentration of calcium, one of most important ubiquitous second messengers, usually increases in response to the biotic or abiotic stress. While at $24 \mathrm{~h}$ two genes associated to calcium homeostasis showed a down regulation, at $48 \mathrm{~h}$ a significant up-regulation was observed for transcripts encoding calmodulins, calmodulin-binding proteins, cal cium-dependent protein kinases and calcium-binding calreticulins.

Overall, the transcriptional data indicated that tomato response to $M$. euphorbiae is based on the concurrent contribution of different cellular signals.

\section{Transcription related genes}

Seventy-two differentially expressed genes were annotated as involved in the regulation of transcription (Additional file 1: Table S2, S3, S4). Compared to other categories, at 
both 24 and $48 \mathrm{~h}$ the number of overexpressed genes was much larger than the number of downregulated genes. The most abundant class of upregulated genes at $48 \mathrm{~h}$ was the one coding for Pentatricopeptide repeat-containing (PPR) proteins. The PPR is a degenerate 35 amino acid motif that occurs in multiple tandem copies in members of a recently recognized eukaryotic gene family, which is relatively small in both animal and fungal kingdom but largely expanded in plants $[35,36]$. Although the role of the hundreds of PPR family members in plants has not been clarified, these proteins are usually associated to RNA editing. It is likely that the high number of differentially expressed sequences we found is related to their predicted abundance in the tomato genome, although their simultaneous up regulation may be suggestive of a more rapid RNA decay in organelles under stress conditions. Another class of genes that were only significantly overexpressed is the WRKY family. The two genes upregulated during the whole infestation belong to the family of WRKY transcription factors, which have been long implicated in the regulation of transcriptional response to pathogens. Other up regulated transcription factors involved in plant response to stress were those related to ethylene metabolism, such as the Ethylene-responsive transcription factor 2, Ethylene responsive transcription factor $1 \mathrm{~b}$ and AP2-like ethylene-responsive transcription factors. However, one gene encoding for Et-regulated transcription factors $1 \mathrm{a}$ was repressed at $96 \mathrm{~h}$. Other types of transcription factors implicated in aphid response are members of the RING finger and Zinc finger Family Protein, which play a central role in different biologic process such as pathogen defense response. Different classes of genes involved in transcriptional regulation, including some associated with biotic stress response, were induced by the M. euphorbiae.

\section{Cell wall modification related genes}

Following $M$. euphorbiae attack, tomato plants modulate also the expression of genes involved in cell wall modification. A total of 43 genes were differentially expressed on the three harvest dates (Additional file 1: Table S2, S3, S4). While at the first time of analysis the majority of the differentially expressed genes were upregulated, at $48 \mathrm{~h}$ only three out of 28 genes were overexpressed. Differentially expressed genes included those associated with cellulose synthesis, the control of oriented deposition of cellulose microfibrils and cell wall strength (Cellulose synthase and Kinesin motor family proteins, wax biosynthesis CER1), as well as those coding for enzymes degrading pectin (Polygalactu ronase, Pectinesterase), hemicellulose (Xyloglucan endo transglucosylase/hydrolase 5) and glucans (Endo-1 4beta-glucanase, Glucan endo-1 3-beta-glucosidase 3/5). Concurrently, genes involved in expansion of the cellulose matrix were mainly downregulated (Expansin and Extensin-like).

The data indicated that aphid infestation in tomato elicits a cell wall remodeling that could play a role in aphid resistance, further deterring insect probing and feeding on the unattacked host tissue.

\section{Photosynthesis and primary metabolism related genes}

The other fundamental biological processes in which the differentially expressed genes have been classified were photosynthesis (26 genes) and primary metabolism (77) (Additional file 1: Table S2, S3, S4). The category "photosynthesis" comprise genes coding for proteins involved in photosynthetic electron transport chain and proteins belonging or associated to photosystem I and II complexes. We observed a general down-regulation of the genes associated with the photosynthesis during the whole infestation period, but with the higher number of differentially expressed genes after $48 \mathrm{~h}$. Tomato response included genes involved in the primary metabolism, mainly those related to carbohydrate and lipid metabolism. Genes of these two groups were predominantly down-regulated on all three infestation dates, similarly to those involved in photosynthesis. However at $48 \mathrm{~h}$, eight genes involved in carbohydrate catabolism were also induced. Differences of expression for genes related to protein metabolism, translation, folding, proteolysis and amino acid metabolism (in total, 57 genes) were observed at $24 \mathrm{~h}$ and $48 \mathrm{~h}$ after aphid infestation (Additional file 1: Table S2, S3, S4). One aspartic proteinase nepenthesin-1 gene was strongly upregulated at $48 \mathrm{~h}$ following potato aphid introduction, together with other genes involved in protein turnover (i.e. proteases).

Our data indicated that before the appearance of signs of chlorosis, the progression of aphid attack mostly represses photosynthesis-related genes in leaf as well as those involved in primary metabolism.

\section{Cell maintenance, transport and secondary metabolism related genes}

Seventy-three genes involved in cell maintenance showed differential expression following aphid infestation (Additional file 1: Table S2, S3, S4). This category grouped genes associated with processes that preserve the cell or its components in a stable functional or structural state, such as genes coding for proteins implicated in cell cycle, cellular component organization, cell differentiation, and nucleotide and nucleic acid metabolic processes. In addition, $M$. euphorbiae induced 52 genes encoding proteins with putative function in transport process (i.e. those involved in the directed movement of substances into a living organism by a means of some agent such as a transporter or pore) (Additional file 1: Table S2, S3, S4). A total of 69 
genes associated with the secondary metabolism showed significant differential expression (Additional file 1: Table S2, S3, S4). Among the induced genes, we found twelve Cytochrome $\mathrm{P} 450$ genes, whose expression profile changed during the early stage of infestation from being down- to up-regulated. The Cytochrome P450 belongs to a broad class of enzymes involved in a wide range of biosynthetic reactions. For instance, P450s act at different points of the phenylpropanoid biosynthetic pathway, as well as in the synthesis of plant allelochemicals, (e.g.: insect toxins, repellents or attractants) [37]. At $48 \mathrm{~h}$, the expression of five genes coding for enzymes involved in polyamine metabolism was repressed, (a S-adenosyl-1-methionine synthase, two Arginine decarboxylases, a Spermidine synthase and an Ornithine decarboxylase). These molecules are an integral part of plant stress response, working as antioxidants, free radical scavengers and membrane stabilizers [38]. Additionally at $48 \mathrm{~h}$, a total of 19 genes associated with the phenylpropanoids and alkaloids biosynthesis were downregulated.

\section{Array validation by qRT-PCR of defense-related genes}

To validate the microarray results, the expression of nine differentially expressed genes was analyzed by Real TimePCR. We selected genes annotated in different biological processes (biotic defense response, signaling transduction, phytohormone signaling and transcriptional regulation).
The Additional file 2: Figures S1, S2 and S3 show the relative quantity (RQ) of each target gene in infested plants at each harvest time. The results were consistent to the microarray data, since the genes analysed displayed similar differential gene expression in response to aphids.

\section{Proteomic analysis of $M$. euphorbiae-infested tomato leaves}

We also carried out a proteomic analysis of tomato leaves after $M$. euphorbiae damage. The leaf tissue of control and infested plants at 48 hours following infestation was used for protein extraction. Proteins were subjected to 2-DE analysis and a representative Coomassie-stained gel from control leaves is shown in Figure 5. Peptide spots showing qualitative and statistically different quantitative differences between infested and control plants were further analyzed. Eighty-seven spots were selected as differentially expressed in tomato after aphid damage with a cut-off of a twofold change compared to the control. A database search with data from peptide mass fingerprinting using MALDI-TOF-MS experiments allowed the identification of the protein uniquely present in 45 spots; the remaining ones were analyzed by nanoLC-ESI-LIT-MS/MS, which identified 12 additional unique components. In the residual 30 spots, we detected multiple polypeptide species, which did not allow a quantitative evaluation of the protein expression level. The list of all the identified

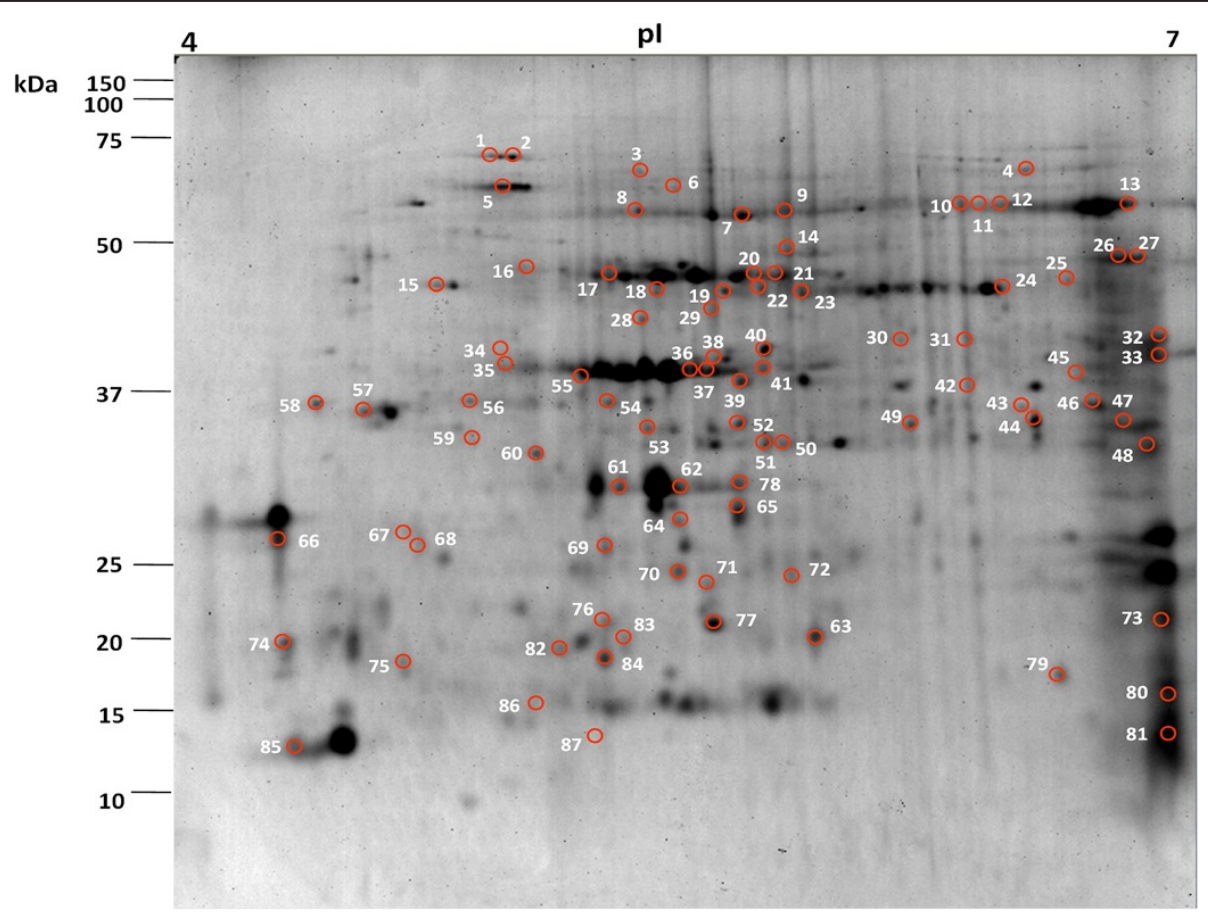

Figure 5 2-DE proteomic map of tomato leaves from non-infested tomato plants. Protein extracts were analyzed in first dimension ( $\mathrm{pH}$ 4-7 linear IPG, $18 \mathrm{~cm})$; second dimension was performed on a vertical slab (12\%T) gel. Protein detection was achieved by using colloidal Coomassie staining. Numbering refers to differentially-represented protein spots in the M. euphorbiae-infested plants, which were then excised, digested and identified by MS procedures as reported in Additional file 1: Table S5. 
proteins is reported in Additional file 1: Table S5, together with the corresponding quantitative variations. The annotation of their protein coding genes indicated that the most represented biological process was "stress and defence response", followed by "primary metabolism" (Figure 6). Among the differentially represented proteins after aphid attack, those involved in the photosynthesis included the oxygen-evolving enhancer protein 1 (OEE1) (spots 35, 36, 37, 41 and 83), oxygen-evolving enhancer protein 2 (OEE2) (spots 61, 62, 65 and 78), photosystem II oxygen-evolving complex protein 3 (spot 73), ATP synthase subunit beta (spots 7, 8 and 9), ATP synthase (spot 42 and 46) and cytochrome f (spot 31). A similar trend was also observed for enzymes of the photorespiration system, such as the RuBisCO activase (spots 17, 20, 21 and 59), RuBisCO decarboxylase small chain (spot 86), aminomethyltransferase (spot 26 and 27) and glycine/ serine hydroxymethyltransferase (spot 11 and 13). As a result of concomitant multiple spot changes often with a negative quantitative trend, some of them showed variations that were suggestive of the occurrence of posttranslational modifications. All proteins occurring in multiple spots have been already reported to be phosphorylated on other plant species (http://phosphat.mpimpgolm.mpg.de and http://www.p3db.org). A down-represen tation of proteins involved in carbohydrate metabolism, namely glycosyl hydrolase family 3 protein (spot 4) and triosephosphate isomerase (spots 44, 49 and 53), was also observed. Among the proteins related to the "transport" category, the mitochondrial outer membrane protein porin (VDAC) (spot 33) and ferredoxin-1, chloroplastic (spot 66 and 74) were up-regulated. Ferredoxin also participates in other reactions in the chloroplast (e.g. redox regulation) [39] and is strongly up-regulated after pathogen attack
[40,41]. Many proteins correlated to defense and stress response were down-regulated in infested plants, except for the Nodulin-related protein (spot 67). Among the down-regulated proteins two were involved in oxidative stress, such as thioredoxin peroxidase 1 (spot 64) and oxidoreductase (spot 23). The category "protein metabolism" included proteins involved in translation, complex assembly, proteolysis and folding (spots 1, 2, 3, 6, 14, 15, 19, 28, 43 and 87). All these proteins, except for the chaperonin 20 (spots 50 and 51), were down-represented, suggesting that protein synthesis and secretion patterns are significantly affected in infested tomato. Finally, glycine-rich RNA-binding protein and RNA recognition motif (RRM)containing protein were down-regulated, as also observed in rice leaf sheaths in response to infestation by the brown planthopper (Nilaparvata lugens) [42].

\section{Protein-mRNA comparative analysis}

A correlation of transcriptomic and proteomic data was performed considering the genes that give rise to the differentially expressed transcripts or proteins. A first comparison, focusing on the functional categories in which the different protein species and transcripts were ranked, indicated a correspondence between the identified GO categories. For both "omics" studies, the functional category "defense and stress response" was the most represented. The match between genes and proteins was very limited, with only 3 mRNA-protein identities (Table 3). Correspondence between differentially expressed genes and proteins was only found considering the transcriptomic data at $48 \mathrm{~h}$. It is therefore likely that factors such as the regulation of mRNA translation and post-translational processing seem to have a more relevant role than the time-lag between transcription

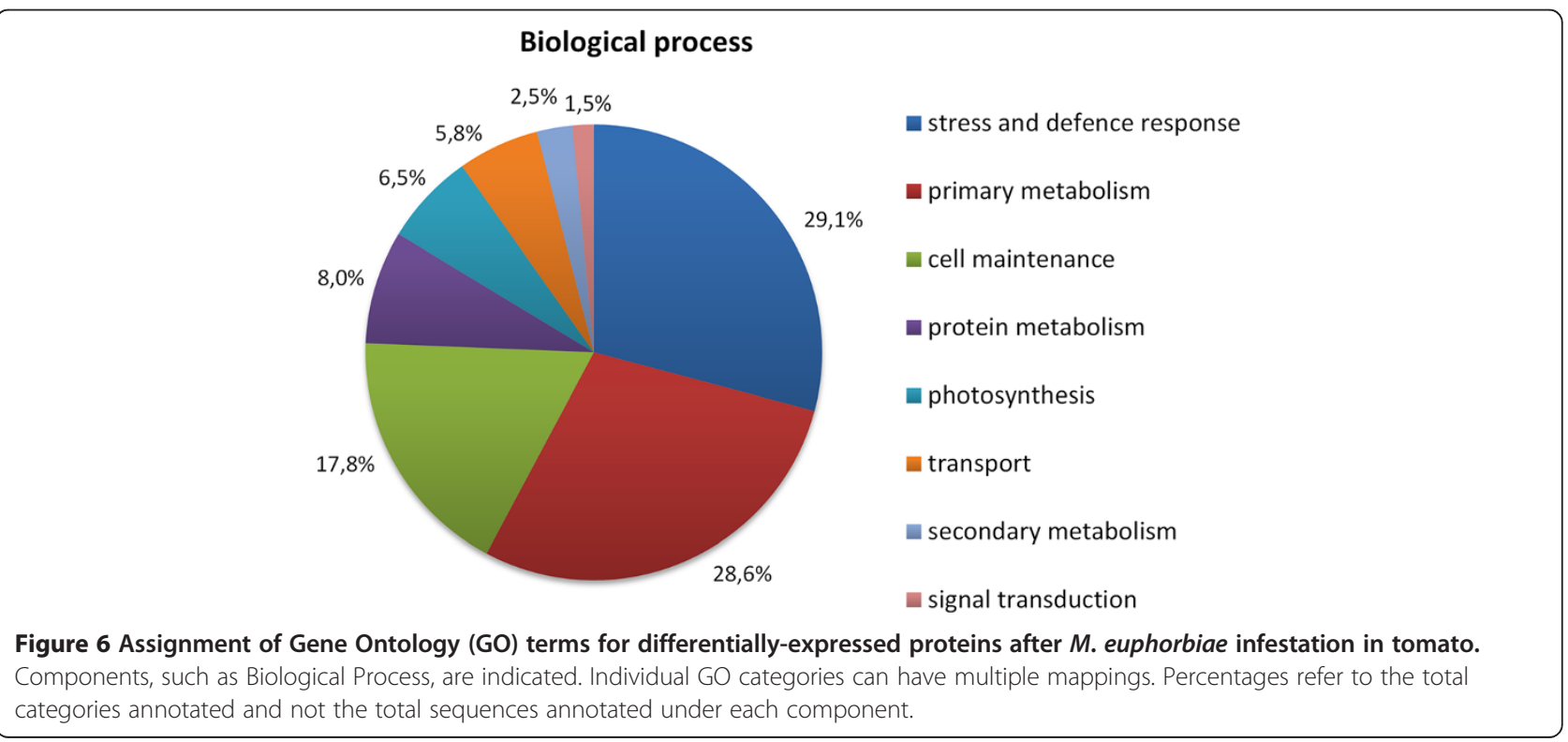


and translation to account for the weak correlation between the "omics" data.

\section{Discussions}

Our study generated extensive data on the expression of a large number of tomato genes and proteins during critical periods of infection with aphids and it provides the first insight into the dynamics of the response to $M$. euphorbiae attack. We analyzed plants at the early stage of infestation, before the development of visible symptoms, and interestingly, the biological processes and molecular pathways affected by aphid feeding were consistent with changes in other plant-aphid interactions [43-45]. However, in the present work a considerable number of tomato genes has been for the first time related to aphid response, thus providing new knowledge on the overlap and interaction between signal transduction pathways and defense response elicited by aphids in tomato.

Even if aphids are able to establish a long-lasting intimate interaction with plant cells, the tomato reaction was clearly variable during the course of the infestation. The number of differentially expressed genes considerably increased from $24 \mathrm{~h}$ to $48 \mathrm{~h}$, reaching also the higher magnitude of expression, and declined at $96 \mathrm{~h}$. This trend may be explained considering that a multifaceted defense response is costly for the plant, which should try to balance defense induction and impact on fitness traits following probing and establishment of a feeding site. Furthermore, in a compatible plant-insect interaction, it is likely that the reduced magnitude of the response at the last stage is the result of plant reprogramming the injured leaf to handle the progression of a successful infestation, along with an active aphid deception of tomato defense $[46,47]$.

For a more integrative view of the tomato-aphid interaction, the transcript profiling was complemented by a proteomic study. We confidently identified 57 proteins that were differentially expressed after insect attack. These proteins belong to a set of biological processes that covered the functional groups of the transcriptional analysis. For instance, response to stress and alteration in photosynthesis were the most abundant categories. The little overlap between trancscriptomic and proteomic data is in accordance to other combined studies in plants $[48,49]$. A likely explanation is related to the features of the proteomic approach [50]. The set of protein spots identified as quantitatively altered by aphids should not be considered comprehensive and other differentially expressed proteins (e.g. transcriprion factors) may have not been detected in 2-D gels due to low concentration and poor solubility in our experimental conditions. Finally, these discrepancies can be due to the post-transcriptional and post-translational events that might be enhanced during tomato defense response to aphid damage [51].

Based on the transcriptomic and the proteomic data, we propose a model to depict the main components involved in aphid response in tomato (Figure 7). Our data indicated that, at the early stage of infestation, $M$. euphorbiae triggers the induction of receptors (e.g. lectin kinase receptors) responsive to wounding and to oligoga lacturonic acids signals [52], but also of genes coding for receptors (e.g. RLKs and LRR-RLKs) that play a central role in signaling following recognition of fungal pathogens [53]. Among others, aphid attack induced a strong activation of a NBS-LRR gene. These proteins detect the presence of disease-causing bacteria, viruses, or fungi by recognizing specific pathogen- or plant-derived effectors [54]. The data strongly support a model in which plants perceive aphids due to tissue damage and to a gene-forgene recognition of aphid-derived elicitors [2]. Currently, it is not known if $M$. euphorbiae, as other aphids, delivers effectors [4], yet the concurrent activation of different receptors would explain why $M$. euphorbiae elicits in tomato a signaling cascade overlapping wounding and pathogen response.

Tomato should perceive aphids essentially through cell membrane receptors and subsequently, the signal transduction exploits various cellular messengers, principally ROS, calcium and stress hormones [14,44,55]. Both transcriptomic and proteomic data indicated differences in genes related to ROS responsive or metabolizing systems (e.g. metallothionein, l-ascorbate oxidase homolog, Respiratory Burst Oxidase-like Protein). In addition, the results underlined the down-regulation of genes associated with the polyamine metabolism, molecules involved in various physiological events such as development, senescence and stress responses including oxidative stresses

Table 3 List of common differentially-expressed transcripts and -represented proteins as obtained from microarray and combined 2-DE/MS studies

\begin{tabular}{|c|c|c|c|c|c|c|}
\hline \multirow{3}{*}{ Description } & \multirow{3}{*}{ Unigene } & \multirow{3}{*}{ Spot } & \multicolumn{4}{|c|}{ Fold change } \\
\hline & & & \multirow[t]{2}{*}{ Proteomic } & \multicolumn{3}{|c|}{ Transcriptomic } \\
\hline & & & & $24 \mathrm{~h}$ & $48 \mathrm{~h}$ & $96 \mathrm{~h}$ \\
\hline Photosystem II oxygen-evolving complex protein 3 & Solyc02g079950.2.1 & 73 & 14.4 & - & -2.31 & - \\
\hline Plastid-lipid associated protein PAP & Solyc09g090330.2.1 & 55 & 0.2 & - & 2.40 & - \\
\hline Ribulose bisphosphate carboxylase small chain 1 & Solyc02g063150.2.1 & 86 & Off & - & -2.23 & - \\
\hline
\end{tabular}




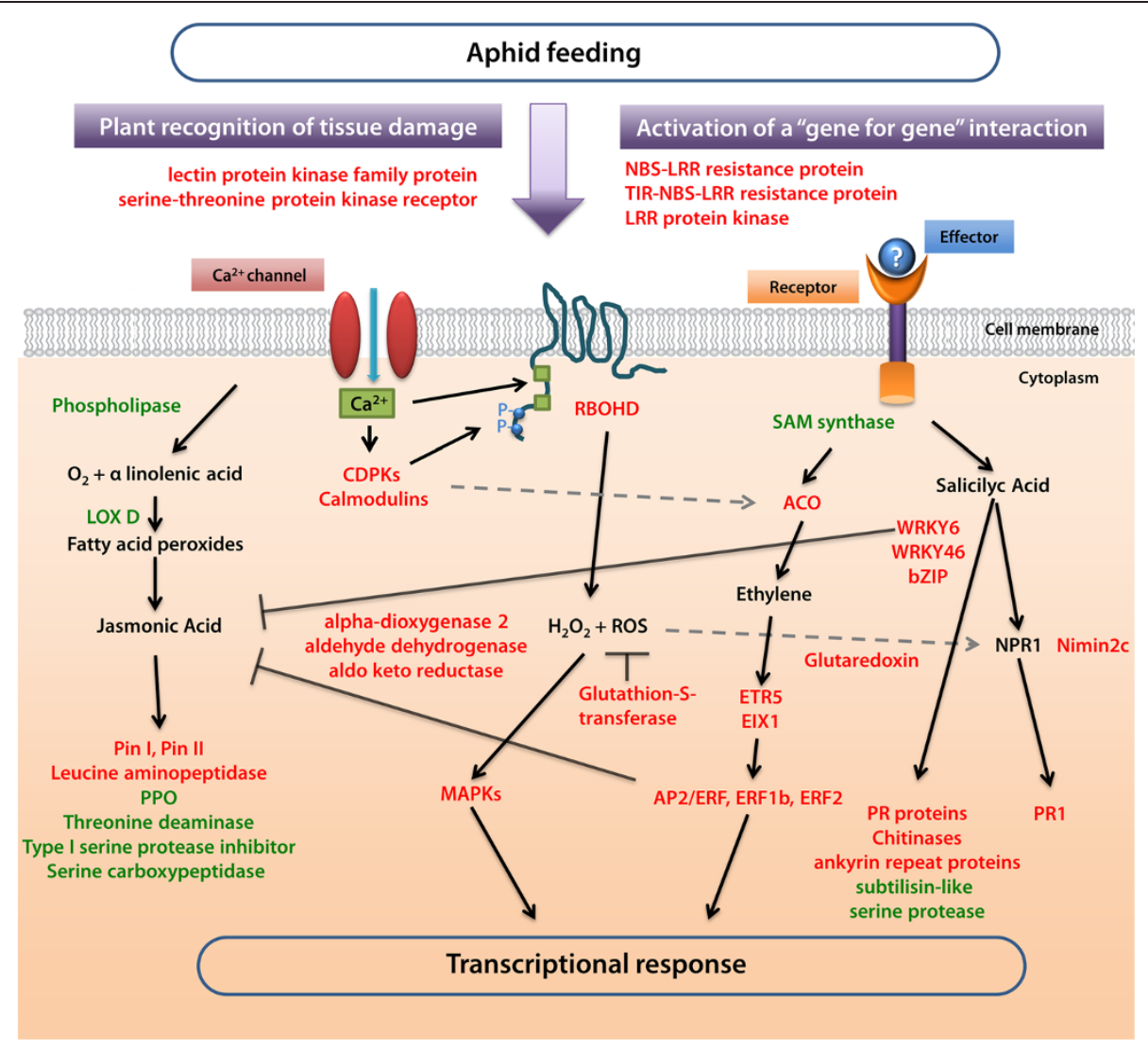

Figure 7 A model summarizing the signaling events and molecular response in tomato following aphid attack. Selected up-regulated genes are in red color, while down-regulated genes are in green. Black lines with arrows indicate activation of enzymatic activities, induction or accumulation of compounds. Grey dashed lines represent indirect positive interactions. Black blunted lines represent inhibitory associations.

See text for details.

[56]. Down-regulation of all those genes following potato aphid infestation would also allow the plant to maintain high $\mathrm{H}_{2} \mathrm{O}_{2}$ levels that can damage the insect midgut [11]. On the other hand, the induction of ROS detoxifying enzymes (e.g. glutaredoxin, glutathione-s-transferase, aldoketo reductase, $\alpha$-DOX), represents an effort of tomato cells to keep ROS levels below toxicity. Among these genes, peroxidases showed the higher expression levels, as also reported for the barley-Diuraphis noxia interaction [45], showing that these enzymes are an important component of the plant reaction to aphids. The tomato response includes genes coding for calcium-dependent kinases (CDPK1, CDPK2, CDPK3) and calcium-binding proteins (Calmodulin-binding protein, Calmodulin-like protein), further confirming the involvement of this ubiquitous intracellular messenger in signal transduction in tomato $[10,16]$. In addition, the concurrent up- and downregulation of genes coding for calcium binding proteins is consistent with an elaborate role of calcium in plant-aphid interaction, since its concentration is at the core of the molecular sabotage that aphids carry out to avoid sieveplate occlusion [57]. Calcium and ROS signaling should be associated through the regulation of RBOHD expression [58]. NADPH oxidases are key plasmalemma-bound enzymes for stress-induced ROS production in plants [58,59]. The presence of EF-hand calcium-binding motifs in the up-regulated tomato $\mathrm{RBOH}$ protein suggests that aphid-induced $\mathrm{Ca}^{2+}$ influxes should affect NADPH oxidase activity through the phosphorylation of the $\mathrm{N}$ terminal region of the protein by CDPKs [60]. The recognition of aphid feeding by tomato receptors triggers the defense reaction through an interplay of different stressrelated phytohormones. What is the contribution of JA and SA to plant defenses against aphids, and which of these hormones has the predominant role is not yet clear. Growing evidence underlines the importance of JAdependent defenses to hamper aphid infestation [17,61]. For instance, jasmonate application improves aphid resistance in different plant species $[11,62,63]$. Furthermore, aphid population growth is boosted or suppressed in Arabidopsis mutants impaired or enhanced in the JA pathway, respectively $[64,65]$. Different studies also emphasize the contribution of SA to plant defenses against aphids and it has also been proposed that the SA pathway has a 
significant role in aphid-resistant genotypes, primarily by promoting antibiosis or repellence $[9,66,67]$. While SA does not seem to be as important as JA in Arabidopsis, only recently, it has been observed that the JA-dependent responses do not significantly contribute to antibiotic defenses against aphids in tomato, while basal resistance is dependent on SA accumulation [68]. Our data showed that several genes responding to SA were up-regulated, whereas a lower number of genes associated to JA biosynthesis, wounding as well as JA-regulated genes were either repressed or showed mild changes in their expression level. Our work stressed the prevailing involvement of SA during the establishment of a tomato-aphid compatible interaction, along with a possible antagonistic crosstalk between the SA- and JA-signaling pathways. Under this perspective, the overexpression of genes involved in ethylene synthesis and signaling (ACO, ERF1b, ERF2, AP2/ERF transcription factor, ETR5) should play a dual role. On one hand it has a synergistic effect by additively improving induced responses $[69,70]$. In parallel, the overexpression of Ethylene Responsive Factor genes should also restrain the JA-pathway [71,72]. This is also supported by the overexpression of harpin-related genes. It has been proposed that stimulation of plants by harpin separates the roles of Et and JA in plant-aphid defense, by promoting Et and SA and suppressing JA signaling [73]. Finally, the induction of genes involved in brassinosteroid synthesis and signaling indicates that this hormone is also involved in the tomato defense response to aphids, most likely by contributing to antagonize the JA pathway [74]. Taken together, the data imply that tomato uses a composite interplay of plant hormones to modulate a JA-independent inducible defense in a compatible aphid interaction [75].

The tomato transcriptional reconfiguration relies in a number of TFs, and a pivotal role is played by WRKY proteins. As some of these proteins mediate the crosstalk between JA-mediated and SA-mediated signals during plant defense, it is reasonable to speculate that the WRKY genes that are continuously overexpressed during the aphid infestation, are involved in the antagonist interaction between SA and JA, as reported for the WRKY70 in Arabidopsis [22,76].

Although the number of differentially expressed genes and proteins that can directly affect aphid performance was low in percentage, the tomato response includes changes in cell structure and plant metabolism that can successfully limit aphid infestation, as also observed in other interactions $[12,13,45,55]$. It is likely that the downregulation of genes involved in the catabolism of cell wall components is a cost-effective strengthening strategy of the cell wall structure. On the other hand, the down-regulation of the Glucan endo-1 3-beta-glucosidase 5 (Gns5), which plays a key role in callose decomposition, may be indicative of the plant's effort to favor sieve tube occlusions, preventing phloem ingestion. Callose deposition is essential to occlude injured sieve elements and avoid sap loss [77]. Hence, the observed pattern of expression suggests that the tomato defense strategy will provide a barrier to the insect stylet and puncturing and it will also limit food supplies to aphids.

Transcriptomic and proteomic data showed a consistent reduction in the category 'photosynthesis'. The transcriptional downregulation of photosynthetic-rela ted genes appears to be a kind of universal adaptive response of plants to biotic stress, which may be compensated by a slower turnover of many photosynthetic proteins [78]. Our data showed that downregulation is seen also at the protein level, indicating that in tomato the induction of a multi-component defense response to aphids requires repression of other cellular functions to ensure metabolic balance [78]. However, protein profiling revealed an increased accumulation of some photosynthesis-related proteins, such as two proteins of PSII system (OEE1 e OEE2) and the Ferredoxin protein. This up-regulation may be related to the role of these proteins in defense, rather than a response of photosynthesis per se. The OEE2 is a downstream protein of the AtGRP-3/WAK1 signaling pathway complex involved in the SA-dependent defense response in Arabidopsis [79]. Similarly, OEE1 exhibits properties and enzyme-modulating activities of a thioredoxin, and it may act protecting cells from the oxygen radicals formed in response to abiotic and biotic stress [80]. Other down-regulated genes and proteins are involved in plant metabolism. Aphids are able to alter the source-sink relationships into the plant by the ingestion of great volumes of phloem sap to fulfill their nutritional requirements [81]. Hence, the negative regulation of genes associated with the primary metabolism may be a strategy adopted by tomato to limit the plant resources assimilation from $M$. euphorbiae. This is also in accordance with the down regulation of different genes involved in carbohydrate and water transport. For instance, genes coding for Aquaporin-like proteins were down-regulated, as in Citrus sinensis plants after $H$. coagulata feeding [82]. On the other hand, different genes associated with amino acid and nitrogen translocation were found to be up-regulated. M. euphorbiae is expected to modify nitrogen allocation in tomato plants by competing with plant sinks and altering the amino acid composition of the phloem sap [83,84]. The observed deregulation confirms that aphids are able to extensively manipulate plant physiology in relation to their nutrition status $[1,85]$. From a metabolic perspective, our data indicated that tomato response presumably allows energy reallocation to prioritize specific defense responses, while modulating other important functions to indirectly reduce aphid performance. 


\section{Conclusion}

Despite the relevant economic impact, not much is known about the molecular recognition and response of tomato plants, and more generally of Solanaceae crops, to aphids. Our study provided a detailed overview of the transcriptomic and proteomic responses of tomato to aphids and led to a more comprehensive understanding of the signaling events and the defense dynamics. Different molecular cues, including those associated to tissue damage and elicitor recognition, lead to a complex, dynamic pattern of expression, in which distinct groups of similarly behaving transcripts were observed. Early events of the response support a gene-for-gene interaction and sensing of a wound-induced damage. The Gene Ontology categories of the identified genes and proteins indicated that the local response is characterized by an increased oxidative stress accompanied by the production of proteins involved in the detoxification of oxygen radicals. Aphids elicit a defense reaction that involves different hormones, with the SA-signaling pathway and stressresponsive SA-dependent genes playing a dominant role. The wound-inducible JA pathway was not strikingly affected, although some JA-dependent genes coding for anti-nutritive proteins were up- or down-regulated. Finally, tomato response is characterized by a reduced investment in photosynthetic proteins and a modification of the expression of various cell wall-related genes.

The identification of genes involved in aphid defense, provides a reference line for the screening of tomato genomic resources, eventually impacting other economically important Solanaceae crops. In the future, targeted functional studies should follow to elucidate the role of the here presented genes in the tomato defense, essential for the development of rational strategies to enhance a durable broad-spectrum resistance to aphids in tomato.

\section{Methods \\ Biological material}

Four weeks old tomato plants (Solanum lycopersicum L. 'Microtom'), grown in insect-proof cages under a $16 \mathrm{~h}$ day cycle at a temperature of $25 \pm 1^{\circ} \mathrm{C}$, were used as host. M. euphorbiae (Thomas) was obtained from an insect culture maintained at the Dipartimento di Agraria, Università di Napoli Federico II, and it was reared on tomato plants 'M82'. Ten $2^{\text {nd }} / 3^{\text {rd }}$ instars were gently transferred onto the abaxial surface of sub-terminal lateral leaves with the help of a paintbrush. Aphids were confined to specific leaves on the plant and their number controlled daily. Uninfested plants were grown under the same conditions. To monitor changes in host gene expression, leaves from infested plants and synchronous aphid-free controls were harvested at 24, 48 and $96 \mathrm{~h}$ after infestation. Aphids were manually removed from leaves and the tissues were frozen in liquid nitrogen for subsequent analysis, carried out on three biological replicates per time point. Leaves of a single replicate were pooled to reduce noise arising from biological variation.

\section{Microarray analysis \\ RNA purification, labeling and oligonucleotide microarray hybridization}

Approximately $200 \mathrm{mg}$ of leaf tissue were ground to fine powder in liquid nitrogen and homogenized in Qiazol solution (Qiagen). RNA was isolated using the RNeasy Plus Mini kit (Qiagen), according to manufacturer's protocol. RNA samples were analyzed quantitatively and qualitatively with a NanoDrop ND-1000 UV-vis Spectrophotometer (NanoDrop Technologies) and by a Bioanalyzer (Agilent Technologies), respectively. Only samples with an RNA Integrity Number (R.I.N.) $>8$ were used for RNA labeling. Total RNA was amplified in the presence of cyanine-3/cyanine-5 labeled CTP using the Agilent low RNA Input Fluorescent Linear Amplification kit (Agilent Technologies), according to manufacturer's instructions. After labeling, reactions were purified using the columns of the Qiagen's RNeasy kit. The quality of labeled targets was determined by calculating the amount of cRNA concentration $(\mathrm{ng} / \mu \mathrm{l})$, Cyanine 3 or cyanine 5 dye concentration (pmol/ $\mu \mathrm{l})$ and RNA absorbance ratio $(260 / 280 \mathrm{~nm})$ using a NanoDrop Spectrophotometer. The specific activity was calculated using the formula: (Concentration of Cy3 or Cy5) / (Concentration of cRNA) * $1000=$ pmol Cy3 or Cy5 per $\mu$ g cRNA. Only samples with a specific activity $\geq 8$ were used for hybridization. Equal amounts of cRNAs from control and from infested plants were mixed together and hybridized to the microarray in a hybridization oven at $65^{\circ} \mathrm{C}$ for 17 hours with rotation speed set at $10 \mathrm{rpm}$.

Gene expression profiling was performed using the Tomato Gene Expression array (4x44k) (Agilent Technologies). This array contains over 44000 probes, representing more than 21,000 tomato transcripts. After hybridization, slides were washed with Gene Expression Wash buffer 1 for 1 minute at room temperature, and Gene Expression Wash buffer 2 for 1 minute at $37^{\circ} \mathrm{C}$. Finally, arrays were treated with the Stabilization and Drying Solution (Agilent Technologies) for 30 seconds at room temperature. Immediately after washing, slides were scanned with the Agilent Dual Laser Microarray Scanner and image data were read out and processed by the Feature Extraction v. 10 software (Agilent Technologies).

\section{Data analysis}

The GeneSpring ${ }^{\circledR} 10$ (Agilent Technologies) software was used to process the microarray data and to associate sample information. Statistical analysis was performed using background-corrected mean signal intensities from each dye channel. Microarray data were normalized using 
intensity-dependent global normalization (LOWESS). Sta tistical testing of differential expression was performed using the Benjamini-Hochberg False Discovery Rate method with a cut off ( $p$-value) $<0.05$. Of the significantly differentially expressed annotated probes, only those with greater than 2-fold increase or 2-fold decrease in expression compared to the controls were used for further analysis. As the array was designed from ESTs before a reference tomato genome sequence was available, for each differentially expressed probe, a similarity analysis was conducted with blastN against SGN Tomato Unigene database (http://solgenomics.net/). We used an e-value threshold of $1^{\mathrm{e}-10}$ to reduce redundancy on the array as well as possible imperfect probe matches. The comparative analysis was performed against a combination of all Tomato Unigenes, BACs, and BAC-end sequences predicted by the ITAG (International Tomato Annotation Group) official annotations, on the SL2.40 tomato genome build. Briefly, when possible, we located each probe on the tomato genome and associated each probe to a transcript of a single gene. Functional annotation of the differentially expressed genes was performed using the Blast2GO software [90] at the default parameters, followed by manual curation.

\section{Microarray validation by real-time quantitative PCR analyses}

Two $\mu$ g total RNA were reverse transcribed by using a SuperScript II Reverse Transcriptase (Invitrogen), following the manufacturer's protocols. To control cDNA synthesis and PCR efficiency, the amplification of the constitutive gene coding for the Elongation Factor 1-a (EF1-a) was carried out according to already published procedures [86]. Real-time PCRs were performed as described [87]. The primers and the size of the expected amplicons are indicated in the Additional file 1: Table $\mathrm{S} 1$. For each target, reactions were performed in triplicate and experiments were carried out on three replicates for treatment. The relative quantification of the gene expression and its statistical test was conducted as previously described [86].

\section{Proteomic analysis}

Proteins were isolated from leaves and resolved and scanned in 2D gels as described [88]. Image analysis was performed using the PDQuest software (Bio-Rad). Spot detection and matching between gels were performed automatically, followed by manual verification. Protein spots were annotated only if detectable in all gels. After normalization of the spot densities against the whole-gel densities, the percentage volume of each spot was averaged for nine different (three replicates of three biological samples) gels and Student's t-test analysis $(p<0.05)$ was performed to find out significant protein fold changes between aphid-challenged and control plants. A two-fold change in normalized spot densities was considered indicative of a differentially-expressed protein. For statistical analysis, data were analyzed by using the SPSS software (IBM) through missing value imputation via K-nearest neighbours analysis, followed by logtransformation of the imputed data and comparison of control and treated values to evaluate corresponding variance (ANOVA), with a non-linear mixed-effects model.

\section{Protein digestion and MS analysis}

Spots from 2-DE were manually excised, triturated, in-gel reduced, S-alkylated and digested with trypsin, as previously reported [88]. Protein digests were subjected to a desalting/concentration step on microZipTip $C_{18}$ pipette tips (Millipore Corp., Bedford, MA, USA) before MALDITOF-MS and/or nanoLC-ESI-LIT-MS/MS analysis. During MALDI-TOF peptide mass fingerprinting (PMF) experiments, peptide mixtures were loaded on the instrument target together with $\alpha$-cyano-4-hydroxycinnamic acid as matrix, using the dried droplet technique. Samples were analysed with a Voyager-DE PRO mass spectrometer (AB Sciex, USA). Peptide mass spectra were acquired in reflectron mode over a mass range of 800-4000 Da, by averaging 50-300 laser shots, and manually inspected to get the corresponding peak lists; internal mass calibration was performed with peptides derived from trypsin auto proteolysis. Data were elaborated using the DataExplorer 5.1 software (AB Sciex). Peptide mixtures were also analyzed by nanoLC-ESI-LIT-MS/MS using a LTQ XL mass spectrometer (Thermo, USA) equipped with Proxeon nanospray source connected to an Easy-nanoLC (Proxeon, Denmark) [89]. Peptide mixtures were separated on an Easy $\mathrm{C}_{18}$ column (100 x $0.075 \mathrm{~mm}, 3 \mu \mathrm{m}$ ) (Proxeon) using a gradient of acetonitrile containing $0.1 \%$ formic acid in aqueous $0.1 \%$ formic acid; acetonitrile ramped from $5 \%$ to $35 \%$ over $24 \mathrm{~min}$, at a flow rate of $300 \mathrm{~nL} / \mathrm{min}$. Spectra were acquired in the range $m / z$ 300-1800. Acquisition was controlled by a data-dependent product ion scanning procedure over the three most abundant ions, enabling dynamic exclusion (repeat count 1 and exclusion duration $1 \mathrm{~min})$. The mass isolation window and collision energy were set to $m / z 3$ and $35 \%$, respectively.

\section{Protein identification}

The MASCOT software package version 2.2.06 (Matrix Science, UK) was used to identify proteins present in gel spots from a tomato Unigene database (http:// solgenomics.net/) (SGN 2009, 68026 sequences) and/or an updated plant non-redundant sequence database (NCBI nr 2009/04, 654658 sequences). Identified SGN entries were associated with corresponding plant proteins by using the BLAST algorithm (http://blast.ncbi. nlm.nih.gov/). In particular, MALDI-TOF PMF data were 
searched using a mass tolerance value of 40-80 ppm; nanoLC-ESI-LIT-MS/MS data were searched by using a mass tolerance value of $2 \mathrm{Da}$ for precursor ion and $0.8 \mathrm{Da}$ for MS/MS fragments. In both cases, searching was performed using trypsin as proteolytic enzyme, a missed cleavages maximum value of 2 and Cys carbamidomethy lation and Met oxidation as fixed and variable modification, respectively. MALDI-TOF PMF candidates with a cumulative MASCOT score $>83$ or nanoLC-ESI-LIT-MS/ MS candidates with more than 2 assigned unique peptides with an individual MASCOT score $>25$, both corresponding to $p<0.05$ for a significant identification, were further evaluated by the comparison with their calculated mass and $\mathrm{pI}$ values, using the experimental values obtained from 2-DE. Each protein identification was verified manually. Protein functional analysis was performed using Blast2GO [90].

\section{Additional files}

Additional file 1: Table S1. Primers used for the expression study and their main features. Table S2: Differentially expressed genes $24 \mathrm{~h}$ after infestation with M. euporbiae. Table S3: Differentially expressed genes $48 \mathrm{~h}$ after infestation with M. euphorbiae. Table S4: Differentially expressed genes $96 \mathrm{~h}$ after infestation with M. euphorbiae. Table S5. Protein species showing quantitative changes during aphid infestation as identified by combined 2-DE and MS procedures.

Additional file 2: Figure S1. Microarray validation and concordance with Real Time results (A) Relative gene expression analysis $24 \mathrm{~h}$ following aphid infestation. The graph displays the relative quantity (RQ) of each target gene in infested plants relative to the calibrator control plants. Asterisks indicate that the $2-\Delta \mathrm{Ct}$ values were significantly different from the calibrator ( $p<0.01$; Student's t-test). (B) The graph displays the concordance between microarray fold change and Real Time RQ values on a linear scale. Figure S2: Microarray validation and concordance with Real Time results (C) Relative gene expression analysis $48 \mathrm{~h}$ following aphid infestation. The graph displays the relative quantity (RQ) of each target gene in infested plants relative to the calibrator control plants. Asterisks indicate that the $2-\Delta \mathrm{Ct}$ values were significantly different from the calibrator ( $p<0.01$; Student's t-test). (D) The graph displays the concordance between microarray fold change and Real Time RQ values on a linear scale. Figure S3: Microarray validation and concordance with Real Time results (E) Relative gene expression analysis $96 \mathrm{~h}$ following aphid infestation. The graph displays the relative quantity (RQ) of each target gene in infested plants relative to the calibrator control plants. Asterisks indicate that the $2-\Delta C \mathrm{C}$ values were significantly different from the calibrator ( $p<0.01$; Student's t-test). (F) The graph displays the concordance between microarray fold change and Real Time RQ values on a linear scale.

\footnotetext{
Abbreviations

2-DE: Two-dimensional gel electrophoresis; ABA: Abscissic acid; CDPK: Calcium dependent protein kinase; Et: Ethylene; GO: Gene ontology; JA: Jasmonic acid; LRR: Leucin rich repeat; MALDI: Matrix-assisted laser desorption/ionization; MS: Mass spectrometry; NADPH: Reduced nicotinamide adenine dinucleotide phosphate; NBS: Nucleotide binding site; PPO: Polyphenol oxidase; PPR: Pentatricopeptide repeat-containing; PR: Pathogenesis related; RLK: Receptor like kinase; ROS: Reactive oxygen specie(s); SA: Salicilic acid; SAR: Systemic acquired resistance; TOF: Time of flight.
}

\section{Competing interests}

The authors declare that they have no competing interests.

\section{Authors' contributions}

VC performed the microarray and the gene expression analysis, analyzed the data and drafted the paper, MC contributed to the microarray experiments and the functional annotation, MR performed the 2D-Electrophoresis, CD carried out the aphid infestation, CDA and GR executed the analysis of the proteomic spots, RM provided assistance for the microarray experiments, AS analyzed the proteomic data and contributed to the writing of the manuscript, FP reviewed the manuscript, RR participated in the study design and reviewed the manuscript, GC designed the study, analyzed the data and wrote the manuscript. All authors read and approved the manuscript.

\section{Acknowledgements}

This research activity was supported by the F.A.R.O. project, Università degli Studi di Napoli e Compagnia San Paolo. The transcriptomic study was partially supported by the P.O.N. Ricerca e Competitività (2007-2013) Genopompro project. The proteomic study was partially supported by grants from the Italian Ministry of Economy and Finance (Progetto Innovazione e Sviluppo del Mezzogiorno - Conoscenze Integrate per Sostenibilità ed Innovazione del Made in Italy Agroalimentare" - Legge n. 191/2009). We thank Adele Cataldo for her technical support throughout the project.

\section{Author details}

'Dipartimento di Agraria, Università degli Studi di Napoli Federico II, 80055 Portici, NA, Italy. ${ }^{2}$ Università degli Studi del Sannio, 82100 Benevento, Italy. ${ }^{3}$ Istituto per il Sistema Produzione Animale in Ambiente Mediterraneo-CNR, 80147 Napoli, Italy. ${ }^{4}$ CEINGE, 80145 Napoli, Italy.

Received: 19 April 2013 Accepted: 26 July 2013

Published: 29 July 2013

\section{References}

1. Thompson GA, Goggin FL: Transcriptomics and functional genomics of plant defence induction by phloem-feeding insects. J Exp Bot 2006, 57(4):755-766.

2. Smith CM, Boyko EV: The molecular bases of plant resistance and defense responses to aphid feeding: current status. Entomologia Experimentalis Et Applicata 2007, 122(1):1-16.

3. Will T, Tjallingii WF, Thonnessen A, Van Bel AJE: Molecular sabotage of plant defense by aphid saliva. Proc Natl Acad Sci USA 2007, 104(25):10536-10541.

4. Hogenhout SA, BOS JIB: Effector proteins that modulate plant-insect interactions. Curr Opin Plant Biol 2011, 14(4):422-428.

5. Walling LL: The myriad plant responses to herbivores. Journal of Plant Growth Regulation 2000, 19(2):195-216.

6. Goggin FL: Plant-aphid interactions: molecular and ecological perspectives. Curr Opin Plant Biol 2007, 10(4):399-408.

7. Ferry N, Stavroulakis S, Guan WZ, Davison GM, Bell HA, Weaver RJ, Down RE, Gatehouse JA, Gatehouse AMR: Molecular interactions between wheat and cereal aphid (Sitobion avenae): Analysis of changes to the wheat proteome. Proteomics 2011, 11(10):1985-2002.

8. Fidantsef AL, Stout MJ, Thaler JS, Duffey SS, Bostock RM: Signal interactions in pathogen and insect attack: expression of lipoxygenase, proteinase inhibitor II, and pathogenesis-related protein P4 in the tomato, Lycopersicon esculentum. Physiol Mol Plant Pathol 1999, 54(3-4):97-114.

9. Moran PJ, Thompson GA: Molecular responses to aphid feeding in Arabidopsis in relation to plant defense pathways. Plant Physiol 2001, 125(2):1074-1085.

10. Moran PJ, Cheng YF, Cassell JL, Thompson GA: Gene expression profiling of Arabidopsis thaliana in compatible plant-aphid interactions. Arch Insect Biochem Physiol 2002, 51(4):182-203.

11. Zhu-Salzman K, Salzman RA, Ahn JE, Koiwa H: Transcriptional regulation of sorghum defense determinants against a phloem-feeding aphid. Plant Physiol 2004, 134(1):420-431.

12. Divol F, Vilaine F, Thibivilliers S, Amselem J, Palauqui JC, Kusiak C, Dinant S: Systemic response to aphid infestation by Myzus persicae in the phloem of Apium graveolens. Plant Mol Biol 2005, 57(4):517-540.

13. Park SJ, Huang YH, Ayoubi P: Identification of expression profiles of sorghum genes in response to greenbug phloem-feeding using CDNA subtraction and microarray analysis. Planta 2006, 223(5):932-947.

14. Kusnierczyk A, Winge P, Jorstad TS, Troczynska J, Rossiter JT, Bones AM: Towards global understanding of plant defence against aphids - timing 
and dynamics of early Arabidopsis defence responses to cabbage aphid (Brevicoryne brassicae) attack. Plant Cell Environ 2008, 31(8):1097-1115.

15. Delp G, Gradin T, Ahman I, Jonsson LMV: Microarray analysis of the interaction between the aphid Rhopalosiphum padi and host plants reveals both differences and similarities between susceptible and partially resistant barley lines. Mol Genet Genomics 2009, 281(3):233-248.

16. Botha AM, Swanevelder ZH, Lapitan NLV: Transcript Profiling of Wheat Genes Expressed During Feeding by Two Different Biotypes of Diuraphis noxia. Environ Entomol 2010, 39(4):1206-1231.

17. Kusnierczyk A, Tran DHT, Winge P, Jorstad TS, Reese JC, Troczynska J, Bones AM: Testing the importance of jasmonate signalling in induction of plant defences upon cabbage aphid (Brevicoryne brassicae) attack. BMC Genomics 2011, 12:43.

18. Kusnierczyk A, Winge P, Midelfart H, Armbruster WS, Rossiter JT, Bones AM: Transcriptional responses of Arabidopsis thaliana ecotypes with different glucosinolate profiles after attack by polyphagous Myzus persicale and oligophagous Brevicoryne brassicae. J Exp Bot 2007, 58(10):2537-2552.

19. McKinley RG, Spaull AM, Straub RW: Pests of Solanaceous crops. In Vegetable crop pests. Edited by McKinley RG. Boca Raton, FL, USA: CRC Press; 1992:263-326.

20. Cheong $\mathrm{YH}$, Chang HS, Gupta R, Wang X, Zhu T, Luan S: Transcriptional profiling reveals novel interactions between wounding, pathogen, abiotic stress, and hormonal responses in Arabidopsis. Plant Physio/ 2002, 129(2):661-677.

21. Thaler JS, Humphrey PT, Whiteman NK: Evolution of jasmonate and salicylate signal crosstalk. Trends Plant Sci 2012, 17(5):260-270.

22. Shim JS, Jung C, Lee S, Min K, Lee YW, Choi Y, Lee JS, Song JT KKJ, Choi YD: AtMYB44 regulates WRKY70 expression and modulates antagonistic interaction between salicylic acid and jasmonic acid signaling. Plant $J$ 2012, 73(3): 483-495

23. Ling H, Zhao JY, Zuo KJ, Qiu CX, Yao HY, Qin J, Sun XF, Tang KX: Isolation and expression analysis of a GDSL-like lipase gene from Brassica napus L. J Biochem Mol Biol 2006, 39(3):297-303.

24. Lee KA, Cho TJ: Characterization of a salicylic acid- and pathogen-induced lipase-like gene in Chinese cabbage. J Biochem Mol Biol 2003, 36(5):433-441.

25. Oh IS, Park AR, Bae MS, Kwon SJ, Kim YS, Lee JE, Kang NY, Lee SM, Cheong H, Park OK: Secretome analysis reveals an Arabidopsis lipase involved in defense against Alternaria brassicicola. Plant Cell 2005, 17(10):2832-2847.

26. Hong JK, Choi HW, Hwang IS, Kim DS, Kim NH, Choi DS, Kim YJ, Hwang BK Function of a novel GDSL-type pepper lipase gene, CaGLIP1, in disease susceptibility and abiotic stress tolerance. Planta 2008, 227(3):539-558.

27. Kawano T: Roles of the reactive oxygen species-generating peroxidase reactions in plant defense and growth induction. Plant Cell Rep 2003, 21(9):829-837.

28. Rouhier N, Lemaire SD, Jacquot JP: The role of glutathione in photosynthetic organisms: Emerging functions for glutaredoxins and glutathionylation. In: Annual Review of Plant Biology. vol. 2008, 59:143-166.

29. Mou Z, Fan WH, Dong XN: Inducers of plant systemic acquired resistance regulate NPR1 function through redox changes. Cell 2003, 113(7):935-944.

30. Jin Y, Penning TM: Aldo-keto reductases and bioactivation/detoxication. In: Annual Review of Pharmacology and Toxicology. vol. 2007, 47:263-292.

31. Sunkar R, Bartels D, Kirch HH: Overexpression of a stress-inducible aldehyde dehydrogenase gene from Arabidopsis thaliana in transgenic plants improves stress tolerance. Plant J 2003, 35(4):452-464.

32. Weigel RR, Bauscher C, Pfitzner AJP, Pfitzner UM: NIMIN-1, NIMIN-2 and NIMIN-3, members of a novel family of proteins from Arabidopsis that interact with NPR1/NIM1, a key regulator of systemic acquired resistance in plants. Plant Mol Biol 2001, 46(2):143-160.

33. Zwicker S, Mast S, Stos V, Pfitzner AJP, Pfitzner UM: Tobacco NIMIN2 proteins control PR gene induction through transient repression early in systemic acquired resistance. Mol Plant Pathol 2007, 8(4):385-400.

34. Wang WX, Vinocur B, Shoseyov O, Altman A: Role of plant heat-shock proteins and molecular chaperones in the abiotic stress response. Trends Plant Sci 2004, 9(5):244-252.

35. O'Toole N, Hattori M, Andres C, lida K, Lurin C, Schmitz-Linneweber C, Sugita M, Small I: On the expansion of the pentatricopeptide repeat gene family in plants. Mol Biol Evol 2008, 25(6):1120-1128.

36. Saha D, Prasad AM, Srinivasan R: Pentatricopeptide repeat proteins and their emerging roles in plants. Plant Physiol Biochem 2007, 45(8):521-534.

37. Schuler MA: The role of cytochrome P450 monooxygenases in plant-insect interactions. Plant Physiol 1996, 112(4):1411-1419.
38. Velikova V, Yordanov I, Edreva A: Oxidative stress and some antioxidant systems in acid rain-treated bean plants - Protective role of exogenous polyamines. Plant Sci 2000, 151(1):59-66.

39. Knaff DB, Hirasawa M: Ferredoxin-dependent chloroplast enzymes. Biochimica Et Biophysica Acta 1991, 1056(2):93-125

40. Dayakar BV, Lin HJ, Chen CH, Ger MJ, Lee BH, Pai CH, Chow D, Huang HE, Hwang SY, Chung MC, et al: Ferredoxin from sweet pepper (Capsicum annuum L.) intensifying harpin(pss)-mediated hypersensitive response shows an enhanced production of active oxygen species (AOS). Plant Mol Biol 2003, 51(6):913-924.

41. Huang HE, Ger MJ, Chen CY, Pandey AK, Yip MK, Chou HW, Feng TY: Disease resistance to bacterial pathogens affected by the amount of ferredoxin-I protein in plants. Mol Plant Pathol 2007, 8(1):129-137.

42. Wei Z, Hu W, Lin QS, Cheng XY, Tong MJ, Zhu LL, Chen RZ, He GC: Understanding rice plant resistance to the Brown Planthopper (Nilaparvata lugens): A proteomic approach. Proteomics 2009, 9(10):2798-2808.

43. De Vos M, Van Oosten VR, Van Poecke RMP, Van Pelt JA, Pozo MJ, Mueller MJ, Buchala AJ, Metraux JP, Van Loon LC, Dicke M, et al: Signal signature and transcriptome changes of Arabidopsis during pathogen and insect attack. Mol Plant Microbe Interact 2005, 18(9):923-937.

44. Kempema LA, Cui XP, Holzer FM, Walling LL: Arabidopsis transcriptome changes in response to phloem-feeding silverleaf whitefly nymphs. Similarities and distinctions in responses to aphids. Plant Physiology 2007 143(2):849-865.

45. Gutsche A, Heng-Moss T, Sarath G, Twigg P, Xia Y, Lu G, Mornhinweg D: Gene expression profiling of tolerant barley in response to Diuraphis noxia (Hemiptera: Aphididae) feeding. Bull Entomol Res 2009, 99(2):163-173.

46. Walling $L L$ : Avoiding effective defenses: Strategies employed by phloem-feeding insects. Plant Physiol 2008, 146(3):859-866.

47. Consales F, Schweizer F, Erb M, Gouhier-Darimont C, Bodenhausen N, Bruessow F, Sobhy I, Reymond P: Insect oral secretions suppress wound-induced responses in Arabidopsis. J Exp Bot 2012, 63(2):727-737.

48. Fan J, Chen CX, Yu QB, Brlansky RH, Li ZG, Gmitter FG: Comparative iTRAQ proteome and transcriptome analyses of sweet orange infected by "Candidatus Liberibacter asiaticus". Physiol Plant 2011, 143(3):235-245.

49. Valledor L, Jorrin JV, Rodriguez JL, Lenz C, Meijon M, Rodriguez R, Canal MJ: Combined Proteomic and Transcriptomic Analysis Identifies Differentially Expressed Pathways Associated to Pinus radiata Needle Maturation. J Proteome Res 2010, 9(8):3954-3979.

50. Belle A, Tanay A, Bitincka L, Shamir R, O'Shea EK: Quantification of protein half-lives in the budding yeast proteome. Proc Natl Acad Sci USA 2006 103(35):13004-13009.

51. Spoel SH, Tada Y, Loake GJ: Post-translational protein modification as a tool for transcription reprogramming. New Phytol 2010, 186(2):333-339.

52. Riou C, Herve C, Pacquit V, Dabos P, Lescure B: Expression of an Arabidopsis lectin kinase receptor gene, lecRK-a1, is induced during senescence, wounding and in response to oligogalacturonic acids. Plant Physiol Biochem 2002, 40(5):431-438.

53. Afzal AJ, Wood AJ, Lightfoot DA: Plant receptor-like serine threonine kinases: Roles in signaling and plant defense. Mol Plant Microbe Interact 2008, 21(5):507-517.

54. Martin GB, Bogdanove AJ, Sessa G: Understanding the functions of plant disease resistance proteins. Annu Rev Plant Biol 2003, 54:23-61.

55. Couldridge C, Newbury HJ, Ford-Lloyd B, Bale J, Pritchard J: Exploring plant responses to aphid feeding using a full Arabidopsis microarray reveals a small number of genes with significantly altered expression. Bull Entomol Res 2007, 97(5):523-532.

56. Alcazar R, Marco F, Cuevas JC, Patron M, Ferrando A, Carrasco P, Tiburcio AF, Altabella T: Involvement of polyamines in plant response to abiotic stress. Biotechnol Lett 2006, 28(23):1867-1876.

57. Will T, Kornemann SR, Furch ACU, Tjallingii WF, Van Bel AJE: Aphid watery saliva counteracts sieve-tube occlusion: a universal phenomenon? J Exp Biol 2009, 212(20):3305-3312

58. Wu JQ, Baldwin IT: New Insights into Plant Responses to the Attack from Insect Herbivores. In Annual Review of Genetics, Vol 44. Edited by Campbell A, Lichten M, Schupbach G. Palo Alto: Annual Reviews; 2010:1-24.

59. Torres MA, Dangl JL, Jones JDG: Arabidopsis gp91(phox) homologues AtrbohD and AtrbohF are required for accumulation of reactive oxygen intermediates in the plant defense response. Proc Natl Acad Sci USA 2002, 99(1):517-522 
60. Kobayashi M, Ohura I, Kawakita K, Yokota N, Fujiwara M, Shimamoto K, Doke N, Yoshioka H: Calcium-dependent protein kinases regulate the production of reactive oxygen species by potato NADPH oxidase. Plant Cell 2007, 19(3):1065-1080.

61. Gao LL, Anderson JP, Klingler JP, Nair RM, Edwards OR, Singh KB: Involvement of the octadecanoid pathway in bluegreen aphid resistance in Medicago truncatula. Mol Plant Microbe Interact 2007, 20(1):82-93.

62. Bruce TJA, Martin JL, Pickett JA, Pye BJ, Smart LE, Wadhams LJ: cis-Jasmone treatment induces resistance in wheat plants against the grain aphid, Sitobion avenae (Fabricius) (Homoptera: Aphididae). Pest Manag Sci 2003, 59(9):1031-1036.

63. Cooper WR, Goggin FL: Effects of jasmonate-induced defenses in tomato on the potato aphid. Macrosiphum euphorbiae. Entomologia Experimentalis Et Applicata 2005, 115(1):107-115.

64. Ellis C, Karafyllidis L, Turner JG: Constitutive activation of jasmonate signaling in an Arabidopsis mutant correlates with enhanced resistance to Erysiphe cichoracearum, Pseudomonas syringae, and Myzus persicae. Mol Plant Microbe Interact 2002, 15(10):1025-1030.

65. Mewis I, Appel HM, Hom A, Raina R, Schultz JC: Major signaling pathways modulate Arabidopsis glucosinolate accumulation and response to both phloem-feeding and chewing insects. Plant Physiol 2005, 138(2):1149-1162.

66. Morkunas I, Mai V, Gabrys B: Phytohormonal signaling in plant responses to aphid feeding. Acta Physiologiae Plantarum 2011, 33(6):2057-2073.

67. Pegadaraju V, Knepper C, Reese J, Shah J: Premature leaf senescence modulated by the Arabidopsis PHYTOALEXIN DEFICIENT4 gene is associated with defense against the phloem-feeding green peach aphid. Plant Physiol 2005, 139(4):1927-1934.

68. Avila CA, Arevalo-Soliz LM, Jia LL, Navarre DA, Chen Z, Howe GA, Meng QW, Smith JE, Goggin FL: Loss of Function of FATTY ACID DESATURASE7 in Tomato Enhances Basal Aphid Resistance in a Salicylate-Dependent Manner. Plant Physiol 2012, 158(4):2028-2041.

69. Van Loon LC, Geraats BPJ, Linthorst HJM: Ethylene as a modulator of disease resistance in plants. Trends Plant Sci 2006, 11(4):184-191.

70. Von Dahl CC, Baldwin IT: Deciphering the role of ethylene in plant-herbivore interactions. Journal of Plant Growth Regulation 2007, 26(2):201-209

71. Shoji T, Nakajima $K$, Hashimoto T: Ethylene suppresses jasmonate-induced gene expression in nicotine biosynthesis. Plant Cell Physiol 2000, 41(9):1072-1076.

72. Winz RA, Baldwin IT: IV. Insect-induced ethylene reduces jasmonate-induced nicotine accumulation by regulating putrescine $\mathrm{N}$-methyltransferase transcriptsIV. Insect-induced ethylene reduces jasmonate-induced nicotine accumulation by regulating putrescine $\mathrm{N}$-methyltransferase transcripts. Plant Physiol 2001, 125(4):2189-2202.

73. Dong HP, Peng JL, Bao ZL, Meng XD, Bonasera JM, Chen GY, Beer SV, Dong HS: Downstream divergence of the ethylene signaling pathway for harpin-stimulated Arabidopsis growth and insect defense. Plant Physiol 2004, 136(3):3628-3638.

74. Campos ML, De Almeida M, Rossi ML, Martinelli AP, Litholdo CG, Figueira A, Rampelotti-Ferreira FT, Vendramim JD, Benedito VA, Peres LEP: Brassinosteroids interact negatively with jasmonates in the formation of anti-herbivory traits in tomato. J Exp Bot 2009, 60(15):4346-4360.

75. Erb M, Meldau S, Howe GA: Role of phytohormones in insect-specific plant reactions. Trends Plant Sci 2012, 17(5):250-259.

76. Li J, Brader G, Palva ET: The WRKY70 transcription factor: A node of convergence for jasmonate-mediated and salicylate-mediated signals in plant defense. Plant Cell 2004, 16(2):319-331.

77. Furch ACU, Hafke JB, Schulz A, Van Bel AJE: Ca2 + -mediated remote control of reversible sieve tube occlusion in Vicia faba. J Exp Bot 2007, 58(11):2827-2838.

78. Bilgin DD, Zavala JA, Zhu J, Clough SJ, Ort DR, DeLucia EH: Biotic stress globally downregulates photosynthesis genes. Plant Cell Environ 2010, 33(10):1597-1613.

79. Yang EJ, Oh YA, Lee ES, Park AR, Cho SK, Yoo YJ, Park OK: Oxygen-evolving enhancer protein 2 is phosphorylated by glycine-rich protein 3/wall-associated kinase 1 in Arabidopsis. Biochem Biophys Res Commun 2003, 305(4):862-868.

80. Heide $H$, Kalisz HM, Follmann $H$ : The oxygen evolving enhancer protein 1 (OEE) of photosystem II in green algae exhibits thioredoxin activity. J Plant Physiol 2004, 161(2):139-149.
81. Douglas AE: Phloem-sap feeding by animals: problems and solutions. J Exp Bot 2006, 57(4):747-754.

82. Mozoruk J, Hunnicutt LE, Cave RD, Hunter WB, Bausher MG: Profiling transcriptional changes in Citrus sinensis (L.) Osbeck challenged by herbivory from the xylem-feeding leafhopper Homalodisca coagulata (Say) by cDNA macroarray analysis. Plant Sci 2006, 170(6):1068-1080.

83. Voelckel C, Weisser WW, Baldwin IT: An analysis of plant-aphid interactions by different microarray hybridization strategies. Mol Ecol 2004, 13(10):3187-3195.

84. Girousse C, Moulia B, Silk W, Bonnemain JL: Aphid infestation causes different changes in carbon and nitrogen allocation in alfalfa stems as well as different inhibitions of longitudinal and radial expansion. Plant Physiol 2005, 137(4):1474-1484.

85. Giordanengo P, Brunissen L, Rusterucci C, Vincent C, Van Bel A, Dinant S, Girousse C, Faucher M, Bonnemain JL: Compatible plant-aphid interactions: How aphids manipulate plant responses. Comptes Rendus Biologies 2010, 333(6-7):516-523.

86. Corrado G, Sasso R, Pasquariello M, lodice L, Carretta A, Cascone P, Ariati L, Digilio MC, Guerrieri E, Rao R: Systemin regulates both systemic and volatile signaling in tomato plants. J Chem Ecol 2007, 33(4):669-681.

87. Digilio MC, Corrado G, Sasso R, Coppola V, lodice L, Pasquariello M, Bossi S, Maffei ME, Coppola M, Pennacchio F, et al: Molecular and chemical mechanisms involved in aphid resistance in cultivated tomato. New Phytol 2010, 187(4):1089-1101.

88. Rocco M, D'Ambrosio C, Arena S, Faurobert M, Scaloni A, Marra M: Proteomic analysis of tomato fruits from two ecotypes during ripening. Proteomics 2006, 6(13):3781-3791

89. Scippa GS, Rocco M, Ialicicco M, Trupiano D, Viscosi V, Di Michele M, Arena S, Chiatante D, Scaloni A: The proteome of lentil (Lens culinaris Medik.) seeds: discriminating between landraces. Electrophoresis 2010, 31:497-506.

90. Conesa A, Gotz S, Garcia-Gomez JM, Terol J, Talon M, Robles M: Blast2GO: a universal tool for annotation, visualization and analysis in functional genomics research. Bioinformatics 2005, 21(18):3674-3676.

doi:10.1186/1471-2164-14-515

Cite this article as: Coppola et al:: Transcriptomic and proteomic analysis of a compatible tomato-aphid interaction reveals a predominant salicylic acid-dependent plant response. BMC Genomics 2013 14:515.

\section{Submit your next manuscript to BioMed Central and take full advantage of:}

- Convenient online submission

- Thorough peer review

- No space constraints or color figure charges

- Immediate publication on acceptance

- Inclusion in PubMed, CAS, Scopus and Google Scholar

- Research which is freely available for redistribution 